\title{
ARTICLE
}

\section{Age-associated antigen-presenting cell alterations promote dry-eye inducing Th1 cells}

Fang Bian ${ }^{1}$, Yangyan Xiao ${ }^{1,2}$, Flavia L. Barbosa ${ }^{1}$, Rodrigo G. de Souza ${ }^{1}$, Humberto Hernandez ${ }^{1}$, Zhiyuan Yu ${ }^{1}$, Stephen C. Pflugfelder ${ }^{1}$ and Cintia S. de Paiva ${ }^{1}$

Aging is a significant risk factor for dry eye. Here we used a murine aging model to investigate the effects of aging on antigen presenting cells (APCs) and generation of pathogenic T helper (Th)-1 cells. Our results showed that APCs from aged mice accumulate at the conjunctiva, have higher levels of co-activation marker CD86 and lower aldehyde dehydrogenase activity. Using topical ovalbumin peptide as a surrogate antigen, we observed an increased number of antigen-loaded APCs in the draining cervical lymph nodes in the aged group and loss of tight junction protein occludin in the conjunctiva. Aged cervical lymph nodes APCs showed a greater generation of Th1 cells than young APCs in antigen-presentation assays in vitro. Aged lacrimal glands, and draining nodes showed an accumulation of IFN- $\gamma$ producing $C D 4^{+} \mathrm{T}$ cells, while Th-17 cells were present only in aged draining nodes. There was also an age-related increase in $\mathrm{CD} 4^{+} \mathrm{CXCR} 3^{+} \mathrm{IFN}-\gamma^{+}$cells in the conjunctiva, nodes, and lacrimal glands while $\mathrm{CD} 4^{+} \mathrm{CCR}^{+}{ }^{+} \mathrm{IL}-17 \mathrm{~A}^{+}$cells increased in the draining nodes of aged mice. Adoptive transfer of aged $\mathrm{CD} 4^{+} \mathrm{CXCR} 3^{+}$cells into young, naive immunodeficient recipients caused greater goblet cell loss than young $C D 4^{+} \mathrm{CXCR} 3^{+}$donor cells. Our results demonstrate that age-associated changes in APCs are critical for the pathogenesis of age-related dry eye.

Mucosal Immunology (2019) 12:897-908; https://doi.org/10.1038/s41385-018-0127-z

\section{INTRODUCTION}

Aging is the highest significant risk factor for dry eye. It has been reported that $6 \%$ of the population at the age of 40 and as many as $15-33 \%$ of elderly patients over the age of 65 are affected by the disease. ${ }^{1,2}$ Dry eye disease affects millions of people worldwide and is accompanied by ocular discomfort, blurred vision, loss of contrast sensitivity, and a decrease in functional vision. ${ }^{3}$

Age-related changes in the immune system are directly or indirectly related to increased risk of opportunistic infections, cancer, and autoimmunity in the elderly. Aging represents a state of paradox where chronic inflammation develops despite a decline in immune responses. ${ }^{4}$ While increased serum levels of TGF- $\beta$ in centenarians can be considered a biomarker of good health, ${ }^{5}$ increased serum levels of IL-6, and TNF- $a$ are predictors of disability and mortality in octogenarians and centenarians. ${ }^{6}$ Individual differences in regulating pro and anti-inflammatory cytokines may be critical in the outcome of inflammatory immune responses in the elderly. ${ }^{7}$ The changes in the immune system have profound consequences for survival and are reliable predictors of morbidity and mortality in the elderly. ${ }^{4}$

Because of its exposed location, the ocular surface mucosa provides a unique opportunity to study the inflammatory aspects of environmental stress in an aging population. Aged subjects have to cope with prolonged exposure to a myriad of antigens, which, in conjunction with a high inflammatory milieu, may stimulate antigen-presenting cells (APC) that are intimately connected to the environment and are essential initiators of the adaptive immune system. In experimental murine models of dry eye, depletion of APCs blunted the immune response and improved signs of dry eye disease. ${ }^{8}$ Increased expression of HLA-DR and its subsequent decrease after treatment has been used as an endpoint of clinical efficacy in several dry eye clinical trials. ${ }^{9-11}$

A body of evidence has identified that the $T$ helper (Th)1 signature cytokine IFN- $\gamma$ has a pathogenic role in many autoimmune diseases, including dry eye. In the gut, IFN- $\gamma$ promotes intestinal barrier loss. ${ }^{12,13}$ Increased levels of IFN- $\gamma$ in tears, conjunctiva, saliva, and blood have been measured in patients with Sjögren Syndrome (SS) and non-SS associated dry eye disease and also in experimental models of dry eye. ${ }^{14-17}$ IFN- $\gamma$ promotes apoptosis of lacrimal and salivary acini ${ }^{18,19}$ and conjunctival goblet cell dysfunction/loss. ${ }^{20-22}$ IFN- $\gamma$ causes endoplasmic reticulum stress in cultured goblet cells and prevents appropriate folding and secretion of the murine Muc5ac protein. ${ }^{22}$ Furthermore, IFN- $\gamma$ has been shown to block cholinergicstimulated goblet cell secretion. ${ }^{23}$ Goblet cells secrete mucins but also immunoregulatory factors that can modulate dendritic cell activation. ${ }^{24-26}$ We have previously reported that aged C57BL/ 6J (B6) mice have dry eye disease ${ }^{27}$ and that age-associated increased IFN- $\gamma$ expression contributes to goblet cell loss as IFN- $\gamma$ knock-out mice were partially resistant to the aging, dry eye phenotype. $^{28}$

The purpose of this study was to investigate how age-related changes in APCs participate in priming Th- 1 cells. Our results indicate that aged APCs have a mature phenotype at the ocular surface, prime Th-1 cells in antigen-specific assays and Th-1 cells

\footnotetext{
${ }^{1}$ Department of Ophthalmology, Baylor College of Medicine, Houston, TX, USA and ${ }^{2}$ Department of Ophthalmology, the Second Xiangya Hospital, Central South University, Changsha 410011 Hunan Province, China

Correspondence: Cintia S. de Paiva (cintiadp@bcm.edu)

This work was presented in part as an abstract at the annual meeting of the Association for Research in Vision and Ophthalmology, Seattle, Washington, USA May 1-5, 2016.
}

Received: 17 July 2018 Revised: 25 November 2018 Accepted: 16 December 2018

Published online: 29 January 2019 
participate in the development of age-related dry eye associated pathology.

\section{RESULTS}

Accumulation of dendritic cells with aging

Aging is a risk factor for dry eye disease. Our previous publication showed that aged B6 mice spontaneously develop dry eye. ${ }^{27}$ Because dry eye is more frequent in women, 2,29 and aged male mice do not develop corneal barrier disruption (a hallmark of dry eye); ${ }^{28}$ we investigated the effect of aging in aged female B6 mice. APCs are master regulators of immune responses and receive signals from the microenvironment to prime naïve $\mathrm{CD} 4^{+} \mathrm{T}$ cells into different subsets of Th cells. We sought to investigate the phenotype and activation markers of APCs in the conjunctiva and cervical lymph nodes (CLNs) of young and aged female mice. Aging has been shown to affect the function and phenotype of dendritic cells. ${ }^{30,31}$

Evaluation of whole mount palpebral conjunctivae from 8week-old (young) and 24-month-old (aged) B6 female mice by laser scanning confocal microscopy demonstrated an increase in

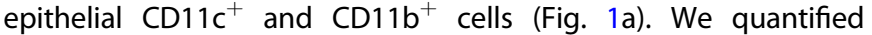
intraepithelial APCs by counting $\mathrm{CD} 11 \mathrm{c}^{+}, \mathrm{CD} 11 \mathrm{~b}^{+}$and $\mathrm{MHC} \mathrm{I}^{+}$ positive cells that were present among epithelial cells or immediately below the basal membrane in palpebral conjunctival cryosections. ${ }^{20,32}$ There was a significant increase in the frequency of intraepithelial $\mathrm{CD}_{11} \mathrm{~b}^{+}, \mathrm{CD} 11 \mathrm{c}^{+}$and $\mathrm{MHC} \mathrm{I}^{+}$cells in the palpebral conjunctiva of aged mice (Fig. 1b, c).

Accumulation of dendritic cells in peripheral tissues is an agerelated phenotype ${ }^{30}$ which is still poorly understood. To investigate if there was a gradient of chemokines that could be recruiting APCs from the circulation, we performed real-time PCR analysis for CCL2, CCL3, CCL4, CCL22, and CXCL13 chemokines in samples obtained from whole thickness conjunctival biopsies. $\mathrm{CCL} 2, \mathrm{CCL} 3$, and CCL4, CCL22 are potent monocytes/macrophages chemoattractants. ${ }^{33,34}$ CXCL13 is a B-cell chemoattractant, but it has been shown to be highly produced by aged $C D 11 c^{+} C D 11 b^{+}$ cells. $^{35,36}$ There was no change in the mRNA levels of CCL2, CCL3, and CCL4 while there was a 3-fold increase in CXCL13 levels in the aged conjunctiva, which was accompanied by a decrease in CCL22 chemokine (Fig. 1d). These results indicate that some other factors yet to be determined are responsible for retaining APCs in the aged conjunctiva.

Since $\mathrm{CD} 11 \mathrm{C}^{+} \mathrm{MHC} \mathrm{I}^{+}$cells can be further divided into $\mathrm{CD} 103^{+}$ or $\mathrm{CD} 11 \mathrm{~b}^{+}$cells, ${ }^{37}$ we then performed flow cytometry analysis in conjunctival and nodes including these markers (Fig. 2a, b). We observed increased CD86 expression in conjunctival MHC ${ }{ }^{+} \mathrm{CD} 11 \mathrm{c}^{+} \mathrm{CD} 11 \mathrm{~b}^{+} \mathrm{CD} 103^{-}$cells from aged mice, while there was a decrease in CD86 expression in MHC $\mathrm{II}^{+} \mathrm{CD} 11 \mathrm{c}^{+} \mathrm{CD} 11 \mathrm{~b}^{-} \mathrm{CD} 103^{+}$and $\mathrm{MHC} \mathrm{II}^{+} \mathrm{CD} 11 \mathrm{c}^{+} \mathrm{CD} 11 \mathrm{~b}^{+} \mathrm{CD} 103^{-}$ cells at the nodes compared to the young group (Fig. $2 c$, d). No change in CD86 expression was observed in the macrophage population with aging neither at the ocular surface nor the draining nodes.

Inflammation has been described as a characteristic of aging. ${ }^{38}$ To investigate this, we performed real-time PCR in full thickness biopsies of the conjunctiva of young and aged mice. Increased IL$1 \beta, M H C I I, I L-12$, and IFN- $\gamma$ mRNA levels were present in aged compared to young conjunctivas (Fig. 2e). Increased immunoreactivity to IL-1 $\beta$ was observed in palpebral conjunctival sections at the basal layer of the conjunctiva in aged mice, while minimal reactivity was seen in young conjunctivas (Fig. $2 \mathrm{f}$ ). IL- $12^{+}$cells were also easily identified in the same area of aged mice. To confirm the increased levels of IFN- $\gamma$, we performed flow cytometry using conjunctival suspensions. There was a significant increase in the frequency and MFI of $\mathrm{CD}^{2} 5^{+} \mathrm{IFN}-\gamma^{+}$cells in the conjunctiva of aged mice (Fig. 2g, h).
These results indicate that an aged conjunctival mucosa is a pro-inflammatory microenvironment that retains more APCs or APC precursors and drives their semi-maturation before migration to the draining CLN.

RA activity in aging in the conjunctiva

Ahadome and colleagues were the first to describe aldehyde dehydrogenases (ALDH)-expressing/retinoic acid (RA)-producing dendritic cells in the conjunctiva. ${ }^{39}$ Our group has also shown conjunctival goblet cells produce biologically active RA that suppresses CD86 expression and IL-12 production by myeloid cells. ${ }^{24}$ The ability to convert retinol (vitamin A) into the immunosuppressive metabolite RA depends on orchestrated sequential conversions by alcohol dehydrogenases and ALDH. Expression analysis of aldehyde dehydrogenase family 1, subfamily A2 (aldh1a2) isoform gene that is found in APCs, showed a significant decrease in the aged conjunctiva (Fig. 2i). Because greater RA synthesizing activity correlates with immune tolerance in skin and gut, ${ }^{40-43}$ we investigated ALDH activity on a per-cell basis in live single cell suspensions from young and aged conjunctiva. There was a significant decrease in total ALDH activity in conjunctival suspensions from aged mice (Fig. 2i).

These results indicate that RA conversion by APC and epithelial cells in the ocular surface microenvironment ${ }^{24}$ may be critical for maintaining local immune tolerance and it is decreased in aged mice. In addition to the intestinal tract, the ocular surface is another mucosal site where RA-producing APCs are very abundant.

Higher uptake of antigens by aged APCs

To determine the migration of antigen-loaded APCs to draining lymph nodes, we topically applied FITC-conjugated OVA peptide 30 min before euthanasia. The OVA peptide has a much smaller molecular weight than full OVA ( $2.3 \mathrm{kDa}$ vs. $45 \mathrm{kDa})$, and we have previously shown the migration of antigens topically applied to the ocular surface into the conjunctival stroma decreases with increasing molecular weight. ${ }^{44}$ Using laser confocal microscopy of whole mount conjunctiva, we confirmed our previous observation of increased diffusion of OVA peptide through goblet cellassociated passages (Fig. 3a). ${ }^{44}$ Compared to young mice, a greater frequency of $\mathrm{OVA}^{+} \mathrm{CD} 11 \mathrm{c}^{+}$and $\mathrm{OVA}^{+} \mathrm{CD} 11 \mathrm{~b}^{+}$cells and increased free OVA peptide in the stroma were readily observed in the aged conjunctiva (Fig. 3a).

Next, we performed flow cytometry on cell suspensions from conjunctivas and draining nodes of eyes that had been topically dosed with fluorescent OVA peptide or vehicle control twice (at 0 and $12 \mathrm{~h}$ before harvesting conjunctiva and CLN at $24 \mathrm{~h}$ ). A greater frequency of OVA peptide ${ }^{+} \mathrm{MHC} \mathrm{II}^{+} \mathrm{CD} 11 \mathrm{~b}^{+} \mathrm{CD} 11 \mathrm{c}^{+}$cells was observed in aged than young conjunctiva $24 \mathrm{~h}$ post application. Similar results were seen in draining lymph nodes, although at much smaller percentages than conjunctiva (Fig. 3b, c), demonstrating both increased uptake by ocular surface APCs and increased migration of antigen-loaded APCs to draining nodes in aged mice. Increased frequency of $\mathrm{CD} 11 \mathrm{~b}^{+} \mathrm{F} 4 / 80^{+} \mathrm{OVA}$ peptide $^{+}$cells was seen only in the aged CLN (Fig. 3b, c).

Because we saw an increased diffusion of surrogate antigens, we sought to investigate the expression of the tight junction protein occludin as a surrogate of barrier function. Occludin is one of the tight junction proteins that is expressed in apical corneal cells. ${ }^{45-48}$ To asses this, we obtained whole mounts of corneas and conjunctivas from both age groups and stained with an antioccludin antibody, as previously described. ${ }^{48}$ We also measured the apical cell area using imaging analysis software, since a smaller apical cell area is a characteristic of dry eye corneas. ${ }^{48}$ We observed an increased frequency of desquamating cells in aged corneas (Fig. 3d, arrows). No evident loss of tight junction protein occludin was seen in aged corneas, although there was greater cytoplasmic staining compared to young corneas (Fig. 3d). There 

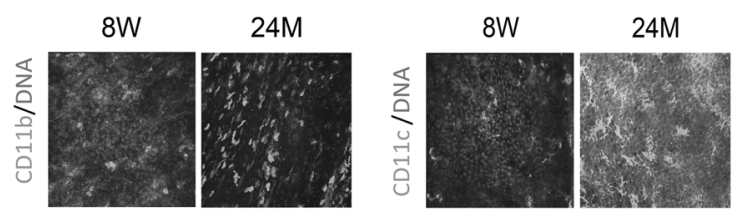

b

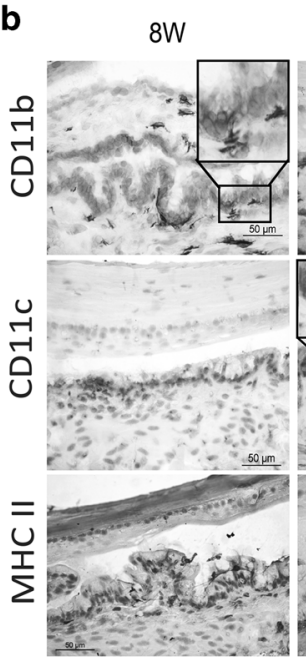

$24 \mathrm{M}$

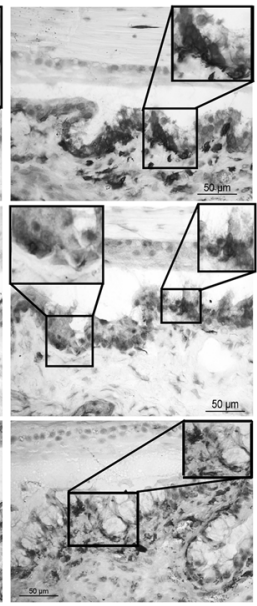

CJ

C

Intraepithelial conjuntival APCs

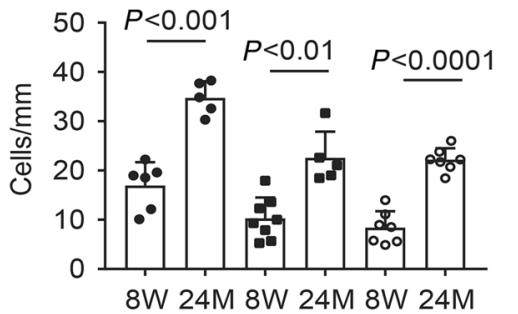

$8 W 24 M$ 8W 24M 8W 24M
- $C D 11 b^{+}$

- $\mathrm{CD} 11 \mathrm{c}^{+}$

$\mathrm{O} \mathrm{MHC} \mathrm{I}{ }^{+}$

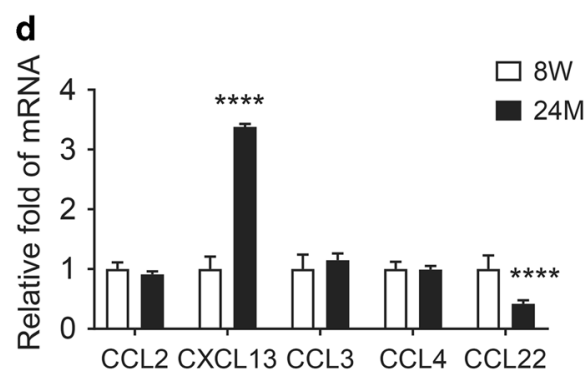

Fig. 1 Aging increases intraepithelial conjunctival APCs. a Apical surface of accumulated images of laser confocal microscopy of whole mount conjunctiva stained for CD11b or CD11c (green) in 8-week (W) and 24-month (24 M) old mice showing using the Z-stack function. Nuclei were stained using propidium iodide (in red, $n=2$ /group). b, c. Representative images of palpebral conjunctival cryosections stained for CD11b, or CD11c or MHC II (red) in (b) that were used to generate the graphs in (c). Insets are a high magnification of the demarcated area. c Intraepithelial conjunctival APCs were counted only if present among epithelial cells or immediately adjacent to the basal membrane. Red positive cells that were present in the stroma were not counted. Each point represents one animal $(n=$ five to seven right eyes/age). $\mathbf{d}$ Whole thickness biopsies of conjunctiva were lysed, and gene expression analysis was performed. Relative fold expression changes of $C-C$ motif chemokine ligand $(\mathrm{CCL})-2,-3,-4,-22$ and $\mathrm{C}-\mathrm{X}-\mathrm{C}$ motif chemokine ligand (CXCL)-13 mRNA in the conjunctiva. Bar graphs show means \pm SD of five-to-six samples per age, biological replicates from two independent experiments were averaged. ${ }^{* * *} P<0.0001$ Mann-Whitney $U$ comparison test

was a marked decrease in apical cell area $(2070 \pm 411$ vs. $1298 \pm$ $395.5 \mathrm{~m}^{2}$; young vs. aged, respectively, $P=0.0012, \quad n=4$ corneas). In the bulbar conjunctiva, loss of tight junction occludin immunoreactivity was evident in aged mice (Fig. 3d). Compared to young group, apical cell surface area was also significantly decreased in the aged bulbar conjunctiva (1658 \pm 245 vs. $1015 \pm$ $137 \mu \mathrm{m}^{2}$; young vs. aged, respectively, $P=0.02, \quad n=4$ conjunctivas).

These results suggest that the combination of increased permeability of surrogate antigens through a leaky epithelium or increased internalization of antigen by APCs contributes to the higher recovery of antigen laden APCs in the aged lymph nodes.

\section{Aged APCs prime Th- 1 cells}

To assess the ability of young and aged APCs to stimulate CD4 ${ }^{+}$ $T$ cells, single cell suspensions from CLN were prepared, pulsed with OVA $_{323-339}$ peptide and mixed with isolated OVA-specific
OT-II CD4 ${ }^{+} \mathrm{T}$ cells as described in the methods. Our pilot studies demonstrated that about $93 \%$ of CLN CD11 ${ }^{+}$cells are MHC II $^{+}$ (data not shown). Proliferation and frequency of $\mathrm{CD}^{+} \mathrm{Foxp}^{+}$, CD4 ${ }^{+}$IFN- $\gamma^{+}$(Th- 1$)$, and $\mathrm{CD} 4^{+} \mathrm{IL}_{-1}-17^{+}$(Th-17) cells and cytokine concentrations in culture supernatants were used as endpoints of $\mathrm{T}$ cell priming. Cells and supernatants were collected after 3-4 days of co-culture. Full cell suspensions of OT-II splenocytes that contained both $\mathrm{CD}^{+}$and APC cells pulsed with $\mathrm{OVA}_{323-339}$ peptide were used as positive controls for kinetic studies. Analysis of proliferating OT-II cells demonstrated that aged CLN APCs induced greater T cell proliferation compared to young APCs (Fig. 4a). This was accompanied by an increased frequency and number of Th-1 cells (Fig. 4b-d) and increased IFN- $\gamma$ concentration in culture supernatants from the aged group (Fig. 4e). No changes in frequency or number of Th-17 cells were observed between the young and aged group (Fig. 4). 
a
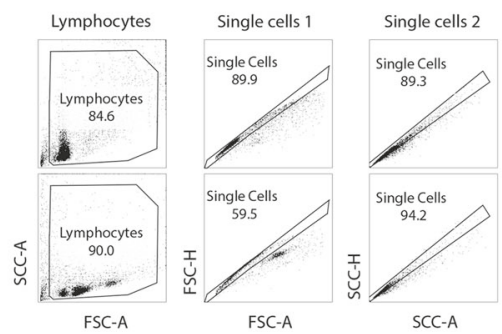

d

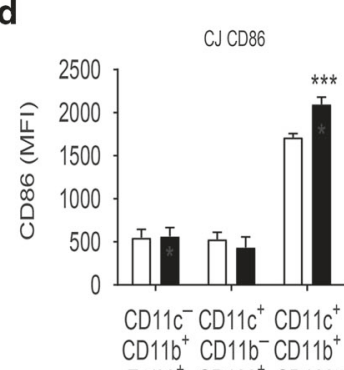

$\mathrm{F} 4 / 80^{+} \mathrm{CD} 103^{+} \mathrm{CD} 103^{-}$ b
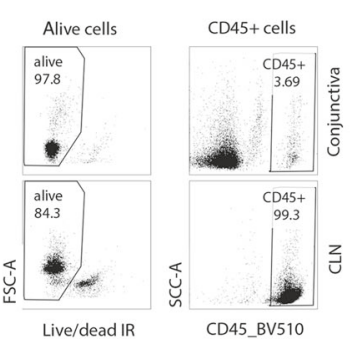
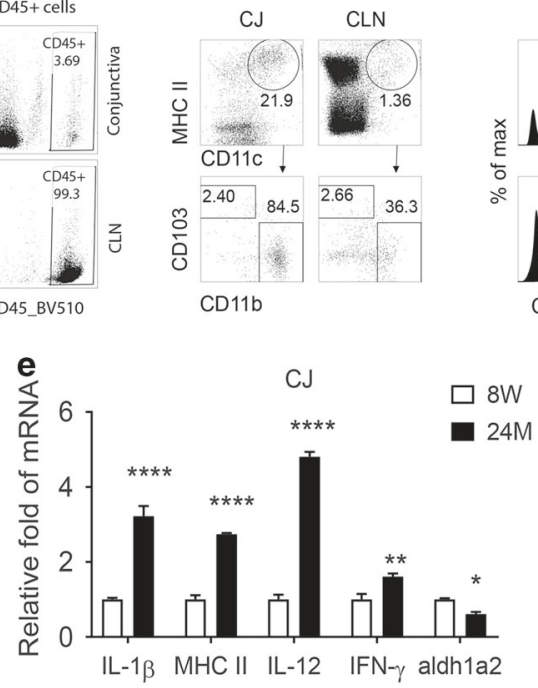

IL-1 $\beta \quad$ MHC II IL-12 IFN- $\gamma$ aldh1a2
C Gated from MHC II ${ }^{+} \mathrm{CD} 11 \mathrm{C}^{+}$

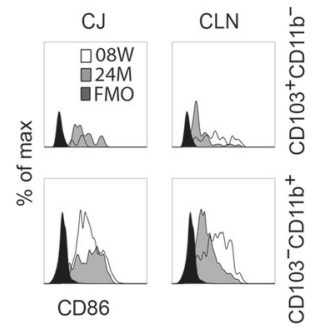

f
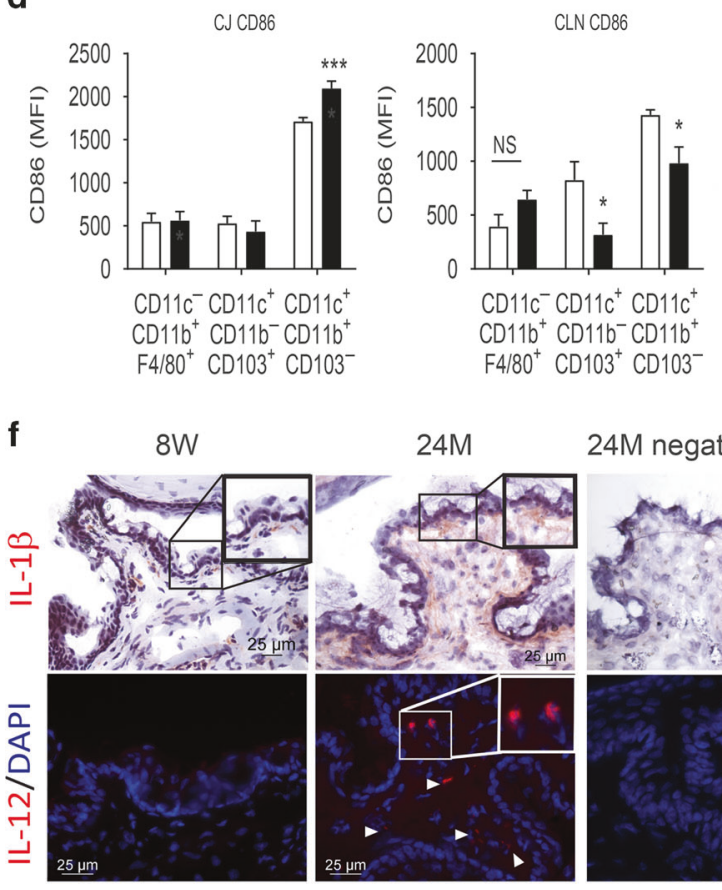

$24 \mathrm{M}$ negative control

g

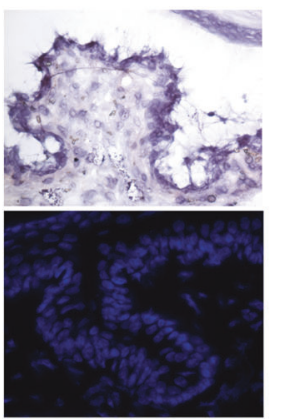

Conjunctiva

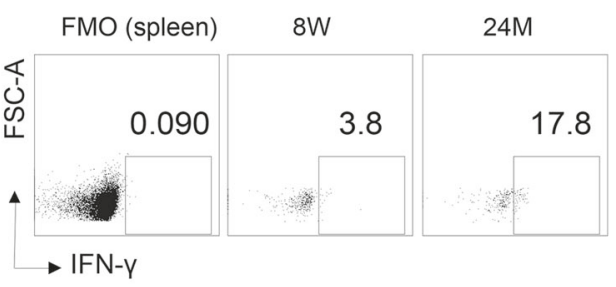

h

i

Conjunctiva

Gated from alive $\mathrm{CD} 45^{+}$cells
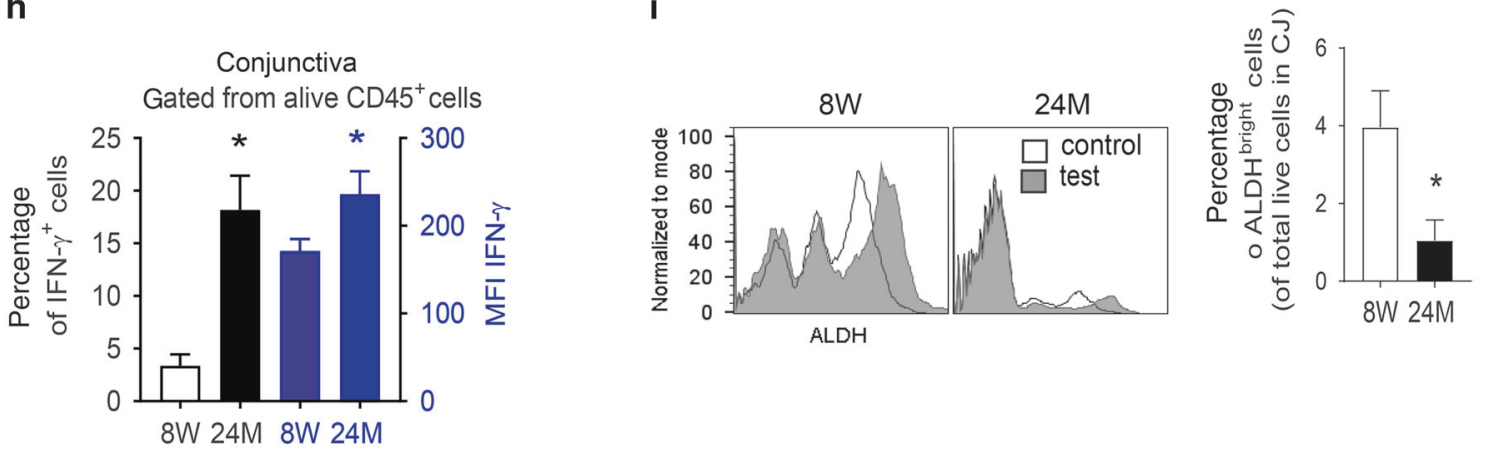

Increased frequency of Th-1 cells in aged ocular tissues

Based on our observations that aged APCs primed Th- 1 cells (Fig. 4), we then asked if mice have increased Th-1 frequency in ocular tissues as they age. Because IL-17 has been implicated in dry eye, ${ }^{15,17,20-22,49-52}$ we also investigated Th-17 cell frequencies in aged ocular tissues. To address this, we prepared single cell suspensions from LG, and CLN from young and aged female B6 mice and performed intracellular staining for IFN- $\gamma$ and IL-17. Our results shown in Fig. 5 demonstrated that Th- 1 cell frequency increased with aging (Fig. 5a, b) in both LG and CLN, while only a systemic increase was seen for Th-17 cells (CLN). Aging was accompanied by an increase in $\mathrm{CD}^{-}$IFN- $\gamma^{+}$cells (LG: $7.2 \pm 4$ vs. $16.05 \pm 7 \%$, young vs. aged, respectively, $P<0.01 ;$ CLN: $0.64 \pm 0.25$ vs. $12.60 \pm 7.7 \%$, young vs. aged, respectively, $P<0.001)$. An increased Th-1/Th-17 ratio was present in aged LG and CLN, demonstrating that the predominant Th response in aged female B6 mice is Th-1 biased (Fig. 5c).

Because Th- 1 cells and Th-17 cells can be isolated based on their CXCR3 or CCR6 chemokine expression (respectively ${ }^{53-55}$ ) we investigated the frequency of $\mathrm{CD}^{+}{ }^{+} \mathrm{CXCR} 3^{+} \mathrm{IFN}-\gamma^{+}$or $\mathrm{CD} 4^{+} \mathrm{CCR}^{+}{ }^{+} \mathrm{L}-17^{+}$cells in the conjunctiva, $\mathrm{CLN}$ and $\mathrm{LGs}$ of young and aged mice. Similarly to the frequency of Th-1 cells, there was a significant increase in the frequency of IFN- $\gamma$ producing $\mathrm{CD}^{+} \mathrm{CXCR3}^{+}$cells in these three tissues in the aged group (Fig. $5 \mathrm{~d}, \mathrm{e}$ ). An increased frequency of IL-17A-producing $\mathrm{CD}^{+}{ }^{+} \mathrm{CR} 6^{+}$cells was only identified in the aged CLN (Fig. $5 \mathrm{~d}$, e). 
Fig. 2 Altered APC phenotype with aging. a Single cell preparations from conjunctiva and cervical lymph nodes (CLN) were prepared and analyzed by flow cytometry. Lymphocytes were identified by forward, and side scatter properties (SSC), single cell gates were drawn, dead cells were excluded, and CD45 $5^{+}$cells were identified. CD11 $\mathrm{c}^{+}$cells were then plotted versus MHC II and further gated into CD103 ${ }^{+}$or $\mathrm{CD}_{11 \mathrm{~b}^{+}}$ cells as shown in (b). b Representative dot plots of flow cytometry analysis of aged APCs in the conjunctiva (CJ) and CLN. CD11 ${ }^{+}$MHC II ${ }^{+}$cells were further divided into $\mathrm{CD} 11 \mathrm{~b}^{+}$or $\mathrm{CD}_{103^{+}}$cells. c Representative histograms showing CD86 fluorescence intensity and fluorescence minus one control (FMO) in CJ and CLN in CD11 $\mathrm{c}^{+} \mathrm{MHC} \mathrm{II}^{+} \mathrm{CD} 103^{+} \mathrm{CD} 11 \mathrm{~b}^{-}$or in $\mathrm{CD} 11 \mathrm{c}^{+} \mathrm{MHC} \mathrm{II}^{+} \mathrm{CD} 103^{-} \mathrm{CD} 11 \mathrm{~b}^{+}$cells. d Accumulative data of flow cytometry analysis showing median fluorescence intensity (MFI) of CD86 in conjunctival and CLN APCs. Mean \pm SEM, $n=$ five mice/ age; biological replicates from two independent experiments were averaged. e Gene expression analysis in whole thickness conjunctival biopsies. Relative fold expression changes of IL-1 $\beta$, major histocompatibility complex (MHC) class II, IL-12, and aldehyde dehydrogenase 1 family member A2 (aldh1a2) mRNA in the conjunctiva. Bar graphs show means \pm SD of five samples per age, biological replicates from two independent experiments were averaged. f Representative images of palpebral conjunctival cryosections stained for IL-1 $\beta$ (red, in immunohistochemistry), or IL-12 (red, I immunofluorescence with DAPI nuclei counterstaining). Insets are a high magnification of the demarcated area. Representative images of five right eyes/age). $\mathbf{g}$ Representative flow cytometry analysis of conjunctiva showing an increase in IFN- $\gamma^{+}$cells with aging. $\mathbf{h}$ Accumulative data showing the frequency of CD45 ${ }^{+} \mathrm{IFN}-\gamma^{+}$and median fluorescence intensity (MFI) of CD45 ${ }^{+}$IFN$\gamma^{+}$cells. Bar graphs show means \pm SD of four samples per age, biological replicates from two independent experiments were averaged. $\mathbf{i}$ Representative histograms (left) and accumulative data (right) of Aldefluor (ALDH) activity in the conjunctiva. Mean \pm SEM, $n=$ eight mice/age (both eyes pooled into one sample); biological replicates from four independent experiments were averaged. ${ }^{*} P<0.05 ;{ }^{* *} P<0.01,{ }^{* * *} P<0.001$, ****P $<0.0001$ Mann-Whitney $U$ age comparison test

Increased pathogenicity of aged Th-1 cells

We have previously shown that IFN- $\gamma$ participates in ageassociated ocular surface disease by demonstrating that IFN- $\gamma$ knock-out (KO) mice were partially resistant to age-related conjunctival goblet cell loss. ${ }^{28}$ To investigate if the increased frequency of Th- 1 cells in aged mice would correlate with increased pathogenicity to the ocular surface, we performed adoptive transfer experiments of Th-1 cells. We have previously shown that adoptively transferred cells from dry eye or aged mice migrate back to the ocular surface and LGs of recipient mice $27,56,57$ and increased levels of IFN- $\gamma$ were present in the conjunctiva of recipients. ${ }^{21}$ Using this experimental design, we isolated $\mathrm{CD}^{+}{ }^{+} \mathrm{CXCR3}{ }^{+}$cells from $\mathrm{CLN}$ and spleens of young and aged B6 mice using a two-step magnetic isolation protocol. Isolated cells were either lysed for RNA analysis or adoptively transferred into young female RAG1KO hosts. In the adoptive transfer experiments, bulk, unfractionated $C D 4^{+} \mathrm{T}$ cells were isolated and adoptively transferred as comparator groups. Gene expression analysis of isolated cells confirmed higher levels of IFN $-\gamma$ mRNA in $\mathrm{CD}^{+}{ }^{+} \mathrm{CXCR}^{+}$cells (aged $>$young, $P<0.0001$ ) with negligible amounts of IL-17A compared to $\mathrm{CD}^{+}{ }^{+} \mathrm{CXCR} 3^{-}$ cells (Fig. 6a).

Evidence of dry eye disease was investigated five weeks posttransfer. We used goblet cell density as an endpoint since goblet cells are susceptible to the deleterious effects of IFN- $\gamma$ (decrease in number, decrease in mucin production and a decrease in calcium release upon agonist stimulation) ${ }^{20-23,28,58}$ and because goblet cell loss is universally seen in the aqueous-deficient dry eye. ${ }^{59,60}$ As shown in Fig. 6 b, c, adoptive transfer of aged T cells induced a significant decrease in mucin-filled goblet cells in RAG1KO recipients compared to young donors; however, this effect was strikingly accentuated in young RAG1KO that received aged $\mathrm{CD}^{+}{ }^{+} \mathrm{CXR3}^{+}$cells. Lymphocytic infiltration in LG of recipients of aged $\mathrm{CD}^{+}{ }^{+} \mathrm{CXCR}^{+}$cells was also observed (Fig. 6c). Taken together, these results indicate that a pathogenic role for Th- 1 cells in age-related dry eye disease.

\section{DISCUSSION}

Aging is a risk factor for dry eye. ${ }^{2}$ Our published studies demonstrated that IFN- $\gamma$ is critical for age-associated conjunctival goblet cell loss as IFN- - KO mice were partially resistant to age effects. ${ }^{28}$ Here we showed that aging is accompanied by significant changes in APC phenotype and function and also by increased frequency of pathogenic Th- 1 cells.

Aged B6 mice showed an altered distribution of APCs in the conjunctiva, with greater accumulation of these cells in the epithelial cell layer. These conjunctival APCs also displayed greater
CD86 expression. It has been shown that goblet cells secrete immunomodulatory factors such as TGF- $\beta$ and retinoic acid ${ }^{24-26}$ and that mice devoid of goblet cells have an altered distribution of conjunctival APCs. ${ }^{61}$ It is possible that age-related goblet cell loss seen in aged $\mathrm{B} 6$ mice $^{27}$ may contribute to the altered distribution and increased activation markers seen in our study, and these findings warrant further investigation.

Our results showed increased inflammation in aged conjunctiva compared to young controls. We observed an increased frequency of $\mathrm{MHC} \mathrm{II}$ cells, increased IFN- $\gamma, \mathrm{IL}-12, \mathrm{IL}-1 \beta$ mRNA and protein levels and elevated CXCL13 mRNA transcripts. While there is no question that the aged conjunctiva is an inflammatory site, it is unclear if this pro-inflammatory microenvironment is a cause or consequence of the accumulation of APCs with aging. In support of the latter, it has been shown that aged dendritic cells have a semi-mature state at baseline and supernatants from dendritic cells from aged subjects activated epithelial cells to produce cytokines in the absence of bacterial stimuli while supernatants from young subjects did not have the same effect. ${ }^{62}$ However, further studies are necessary to dissect the individual contribution to epithelial and APCs; it is possible that this crosstalk is bidirectional.

Our results showed that conjunctival suspensions from aged mice had lower ALDH activity than young. ALDH is responsible for the last step in the conversion of vitamin A (retinol) into its active metabolite retinoic acid. Our results agree with Ahadome and colleagues who were the first to describe that RA-producing dendritic cells are present in conjunctiva. ${ }^{39}$ We have previously shown that aged mice have greater than $50 \%$ conjunctival goblet loss at 24 months of age. ${ }^{27}$ A decrease in goblet cells is an essential part of the dry eye phenotype since our in vitro studies showed that conjunctival goblet cells secrete bioactive RA that can modulate dendritic cell activation markers. ${ }^{24}$ Inflammatory stimuli, such as zymosan and LPS, have been shown to increase ALDH activity. ${ }^{63}$ Despite a pro-inflammatory environment (evidenced by elevated levels of IL-12, IL-1 $\beta$, and IFN- $\gamma$ in the conjunctiva), our results showed that aged APCs failed to upregulate ALDH activity as a compensatory mechanism, maybe due to conjunctival goblet cell loss. ${ }^{27}$ Reduced RA conversion in the eye microenvironment suggests a defect in immune tolerance mechanisms that accompany aging. Supporting our hypothesis, Pinkie mice, which have a $90 \%$ loss of RXRa activity secondary to a mutation of the mouse retinoid $X$ receptor $a$, have increased Th- 1 polarization in vitro with aging and decreased suppressive activity by their Tregs. ${ }^{64}$ Therefore, the combined low expression of Aldh1a2 gene in the conjunctiva and the failure to increase ALDH activity in an inflammatory milieu may favor disruption of mucosal tolerance. 

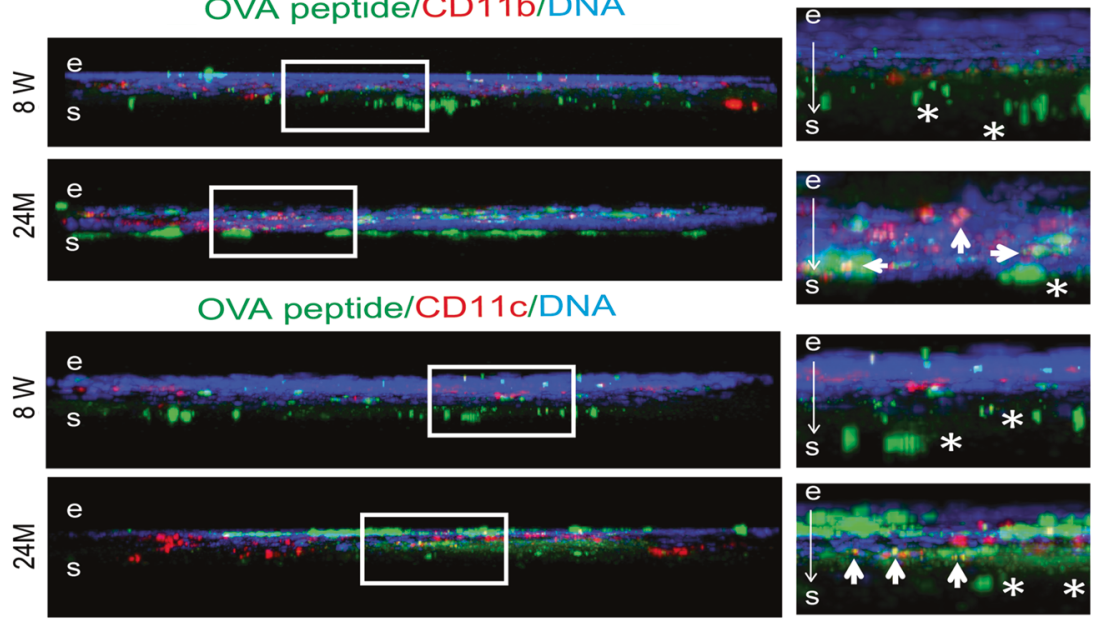

b

OVA p (24h)

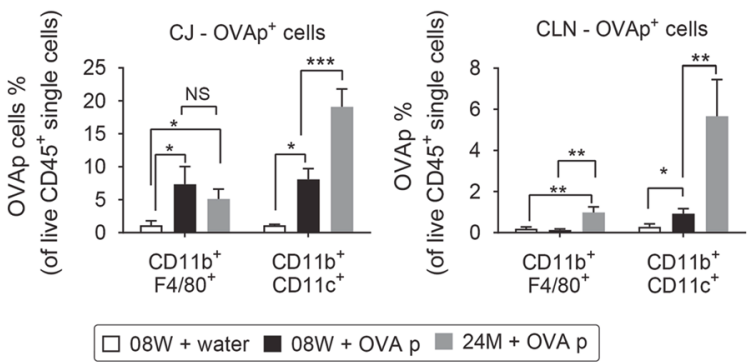

d
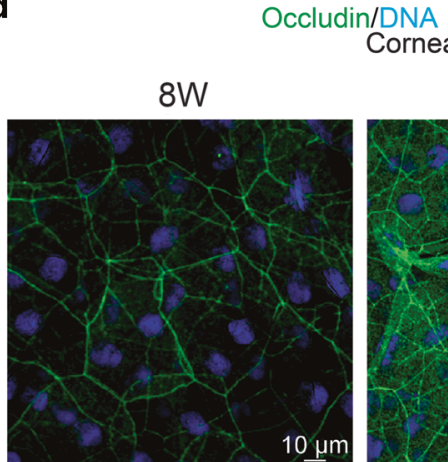

Cornea

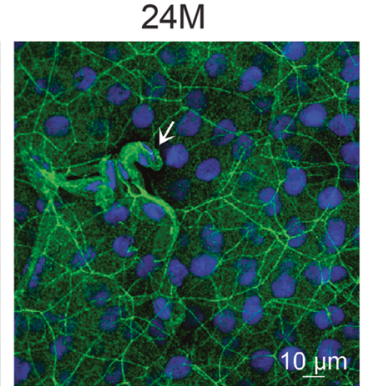

C

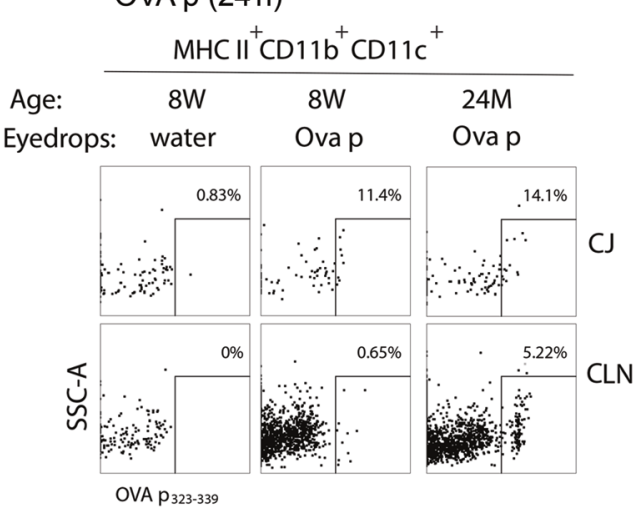

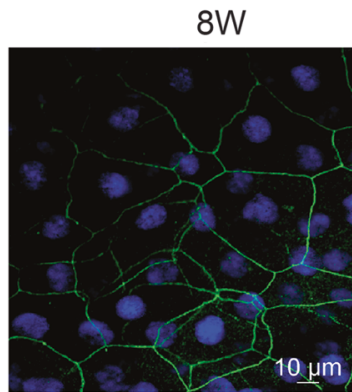

Fig. 3 Greater number of OVA ${ }^{+}$APCs in the ocular surface and draining nodes. a FITC-conjugated OVA peptide (OVAp) was topically applied to the ocular surface of young and aged female mice. Uptake of the fluorescent peptide was evaluated by confocal microscopy thirty minutes after application. Laser confocal microscopy of whole-mount conjunctiva stained for CD11b (a) and CD11c (b) thirty minutes after placing FITC-conjugated OVAp antigen on the ocular surface; Z-stack option from the epithelium (e) to stroma (s) showing the distribution in immune cells and OVAp. Goblet cell associated passages (columns) were easily identified (asterisks). Frequent OVA ${ }^{+} \mathrm{CD}_{11 \mathrm{~b}^{+}}$and OVA ${ }^{+} \mathrm{CD} 1 \mathrm{c}^{+}$cells were seen in aged eyes (arrows). Squares in z-stacks are magnified on the right. $E=$ epithelium, $\mathbf{s}=\mathbf{s t r o m a}$. $\mathbf{n}=\mathbf{t w o}$ animals/age. $\mathbf{b}, \mathbf{c}$ Water or FITC-conjugated OVAp was applied to the ocular surface at 0 and $12 \mathrm{hrs}$. Right, and left conjunctivas (CJ) were harvested and pooled, and cervical lymph nodes (CLN) were collected and prepared for flow cytometry $24 \mathrm{hrs}$ later the first OVAp administration (total of two applications). $\mathrm{CD} 11 \mathrm{c}^{+}$cells were plotted versus MHC II and further gated into $\mathrm{CD}_{103^{+}}$or $\mathrm{CD} 11 \mathrm{~b}^{+}$cells. MHC II ${ }^{+} \mathrm{CD} 11 \mathrm{c}^{-}$cells were identified and plotted versus $\mathrm{F} 4 / 80$ and $\mathrm{CD} 11 \mathrm{~b}$ to gate $\mathrm{MHC} \mathrm{I}{ }^{+} \mathrm{CD} 11 \mathrm{~b}^{+} \mathrm{F} 4 / 80^{+}$cells. Median fluorescence intensity (MFI) of CD86 staining was then analyzed in these populations. Dendritic cells were $\mathrm{MHC} \mathrm{II}^{+} \mathrm{CD} 11 \mathrm{c}^{+} \mathrm{CD} 11 \mathrm{~b}^{+}$and macrophages were $\mathrm{MHC} \mathrm{II}^{+} \mathrm{CD} 11 \mathrm{c}^{-} \mathrm{CD} 11 \mathrm{~b}^{+} \mathrm{F} 4 / 80^{+}$. The frequency of $\mathrm{OVAp}^{+}$cells was then determined in each population. b Accumulative data of flow cytometry analysis. c Representative dot plots of OVAp laden APCs in the conjunctiva and CLN. Means \pm SEM, $n=$ four to seven mice/age; biological replicates from two independent experiments were averaged. d Laser scanning confocal microscopy of whole mount corneas and bulbar conjunctivas stained for occludin (green) with Hoechst 33342 (blue) nuclear counterstaining $(n=3)$. Arrows in the cornea panel indicate desquamating cell and arrowheads indicate loss of occludin immunoreactivity in between two cells. $\mathrm{W}=$ week, $\mathrm{M}=$ month, NS = non-significant, ${ }^{*} P<0.05 ;{ }^{* * P}<0.01,{ }^{* * *} P<0.001$ Mann-Whitney U-test age comparison 
a

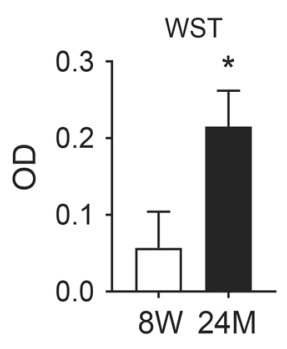

C

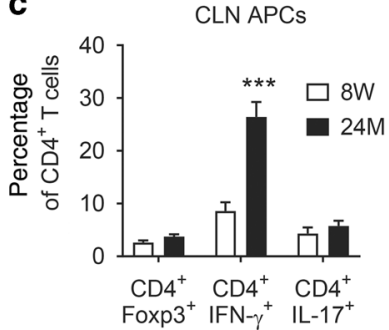

b

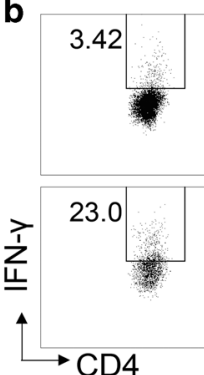

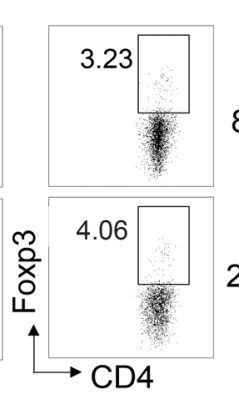

d

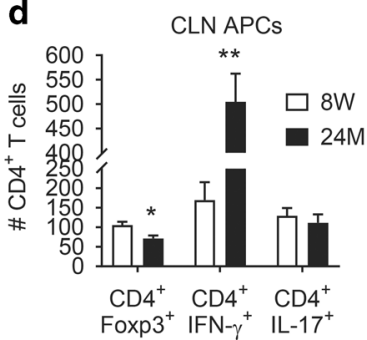

FMO
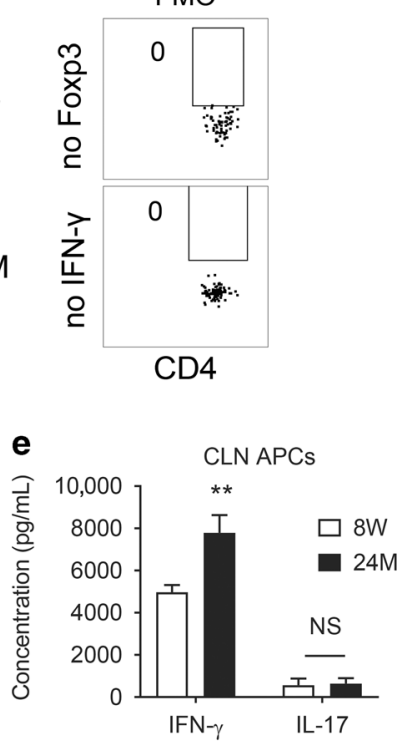

Fig. 4 Aged Antigen presenting cells prime Th-1 cells. Cervical lymph node (CLN) suspensions were prepared from young and aged mice and were pulsed with $\mathrm{OVA}_{323-339}$ peptide for 1 hour before the addition of isolated OT- II CD4 ${ }^{+} \mathrm{T}$ cells. OT-II splenocytes that contained both CD4 ${ }^{+}$T cells and APCs were also pulsed with OVA peptide and used as positive controls. There were 12-16 mice per age/experiment (cells were pooled per experiment) and a total of four independent experiments (total of 48-64 animals). Due to the scarcity of cells, not all endpoints were achieved in all experiments. Cells and supernatants were collected after 3-4 days in culture. a WST-1 proliferation assay of OTII CD4 ${ }^{+} \mathrm{T}$ cells primed by CLN APCs from young and aged mice. Means $\pm \mathrm{SEM}, n=$ six wells/age after co-culture using 12-16 mice/age per experiment. The experiment was repeated with similar results. b Representative dot plots of CD4 ${ }^{+}$IFN- $\gamma^{+}$and $\mathrm{CD}^{+}{ }^{+}$Foxp3 $3^{+}$in of $\mathrm{OT}_{-1 \mathrm{I}}$ $\mathrm{CD} 4^{+} \mathrm{T}$ cells primed by CLN APCs. c-d Accumulative flow cytometry data showing frequency (c) and number (d) of CD4 ${ }^{+}$Foxp $3^{+}, \mathrm{CD}^{+}{ }^{+} \mathrm{IFN}-\gamma^{+}$ and $\mathrm{CD} 4^{+} \mathrm{IL}-17^{+}$cells primed by CLN APCs from young and aged mice. Means \pm SEM of two combined experiments; $n=$ six to eight wells after co-culture using four-five mice/age per independent experiment. e Concentration of IFN- $\gamma$ and IL-17A in cell culture supernatants of OT-II $\mathrm{CD}{ }^{+} \mathrm{T}$ cells primed by CLN APCs. Means \pm SEM of two combined experiments; $n=$ six to eight wells after co-culture using four-five mice/age per independent experiment. ${ }^{*} P<0.05 ;{ }^{*} P<0.01 ;{ }^{* *} P<0.001$; Mann-Whitney U-test age comparison. NS $=$ non-significant; FMO $=$ fluorescence minus one; $8 \mathrm{~W}=8$-week old mice; $24 \mathrm{M}=24$-month old

We have previously shown that in mice devoid of goblet cells, there is an accumulation of dendritic cells and macrophages at the ocular surface and altered surrogate antigen distribution after topical instillation. ${ }^{44}$ Greater recovery of a topically applied surrogate antigen (OVA peptide) was observed in the conjunctiva and draining lymph nodes of aged mice in this study. Our z-stack laser confocal images showed increased free OVA peptide in the conjunctiva of aged compared to young mice. It is possible that greater diffusion of OVA peptide into the epithelium due to inflammation-associated barrier dysfunction could increase the availability of surrogate antigens. Our studies evaluating occludin staining in whole mounts of cornea and bulbar conjunctiva showed a decrease in apical cell area in aged cornea and bulbar conjunctiva, indicating that the apical and larger cells might have already desquamated. This is well observed in experimental dry eye in mice subjected the desiccating stress. ${ }^{48}$ Furthermore, discontinuity of the tight junctions in aged conjunctiva may explain the increased availability of antigens to resident APCs which are now free to migrate to the regional lymph nodes.

It has been demonstrated that IFN- $\gamma$ is pathogenic to the ocular surface and LG acinar epithelial cells, ${ }^{16,20-22}$ two different cell types that are negatively impacted by aging. ${ }^{27,28}$ Our results indicate that aging is accompanied by increased frequency of Th-1 cells not only in the draining nodes but also in LGs. Although Th- 1 and Th-17 cells are readily observed in young mice subjected to desiccation, ${ }^{17,49,65}$ we did not observe an age-related increase in Th-17 in LG or conjunctiva; only in draining lymph nodes. We have previously shown that adoptively transferred cells from dry eye or aged mice migrate back to the ocular surface and LGs of recipient mice $27,56,57$ and increased levels of IFN- $\gamma$ are present in the conjunctiva of recipients. ${ }^{21}$ We have extensively shown that IFN- $\gamma$ is deleterious to the ocular surface: (1) IFN- $\gamma \mathrm{KO}$ mice are resistant to desiccation-induced goblet cells loss but subcutaneous administration of IFN- $\gamma$ into IFN- $\gamma \mathrm{KO}$ mice leads to goblet cells loss, recapitulating the wild-type phenotype; ${ }^{20}$ (2) IFN- $\gamma$ antibody depletion in wild-type mice during desiccating stress improves goblet cell loss; ${ }^{21}$ (3) addition of IFN- $\gamma$ to conjunctiva goblet cell cultures lead to cell death and loss of mucin production; ${ }^{22}$ (4) 15month old IFN- $\gamma$ KO mice have greater number of goblet cells than age-matched wild-type mice. ${ }^{28}$ The results of our adoptive transfer experiments support our hypothesis that aged Th-1 cells are pathogenic to the ocular surface since recipients of aged $\mathrm{CXCR3}^{+}$ cells had the greatest goblet cell loss compared to recipients of aged bulk $\mathrm{CD}^{+}$and young $\mathrm{CD}^{+}{ }^{+} \mathrm{CXR3}^{+}$donors. These experiments highlight that loss of mucosal immune tolerance with aging leads to a spontaneous generation of eye-pathogenic T cells since our experiments did not use any immunization protocols nor autoimmune mice.

Our new findings implicate increased APC maturation and generation of pathogenic Th-1 cells in the pathogenesis of ageassociated dry eye. Further studies are needed to dissect if alterations in the ocular microenvironment are the cause or consequence of age-related dry eye disease.

\section{MATERIALS AND METHODS}

Animals

Breeder pairs of $\mathrm{C} 57 \mathrm{BL} / 6 \mathrm{~J}(\mathrm{~B} 6)$, recombination activating protein one knock-out (RAG1KO) and B6.Cg-Tg (TcraTcrb) 425Cbn/J (OT-II) mice 6-8 weeks old were purchased from The Jackson Laboratory (Bar Harbor, ME) for establishing breeder colonies. Naturally aged female B6 mice were maintained in specificfree pathogen 
a Gated from alive single CD45 cells
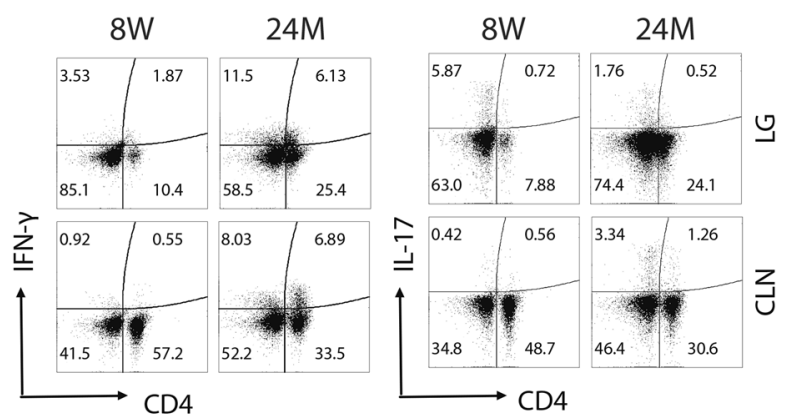

Fluorescent minus One controls (8W)

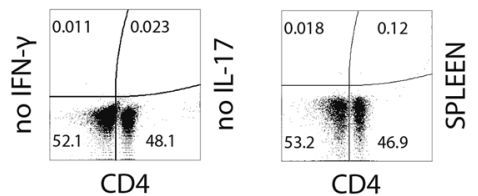

d Gated from alive single $\mathrm{CD} 45^{+} \mathrm{CD} 4^{+}$cells
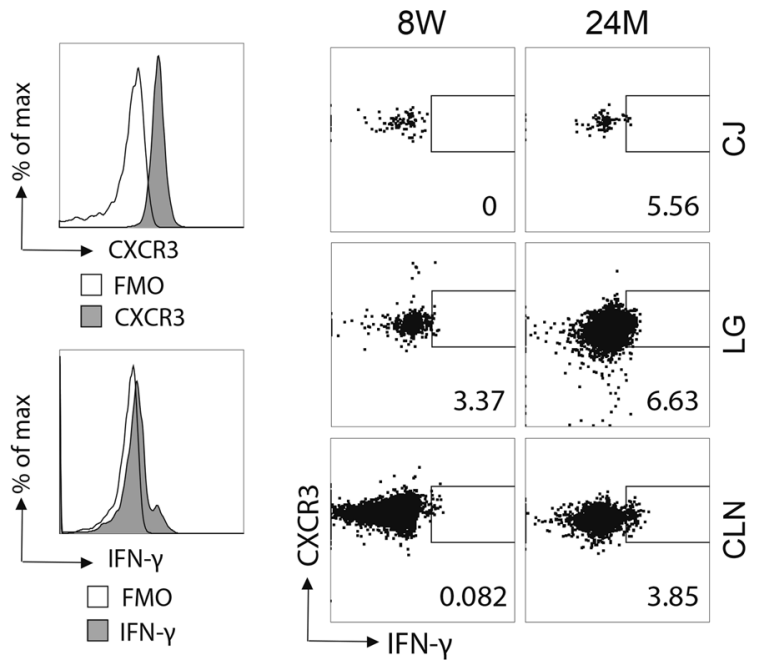

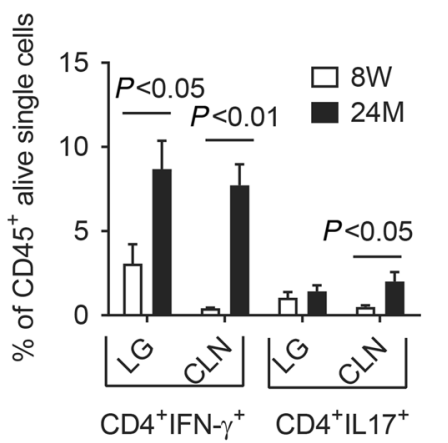

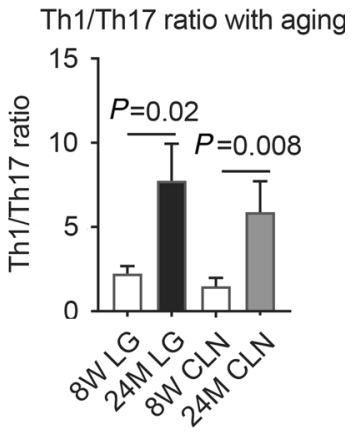

Gated from alive single $\mathrm{CD} 45^{+} \mathrm{CD} 4^{+}$cells
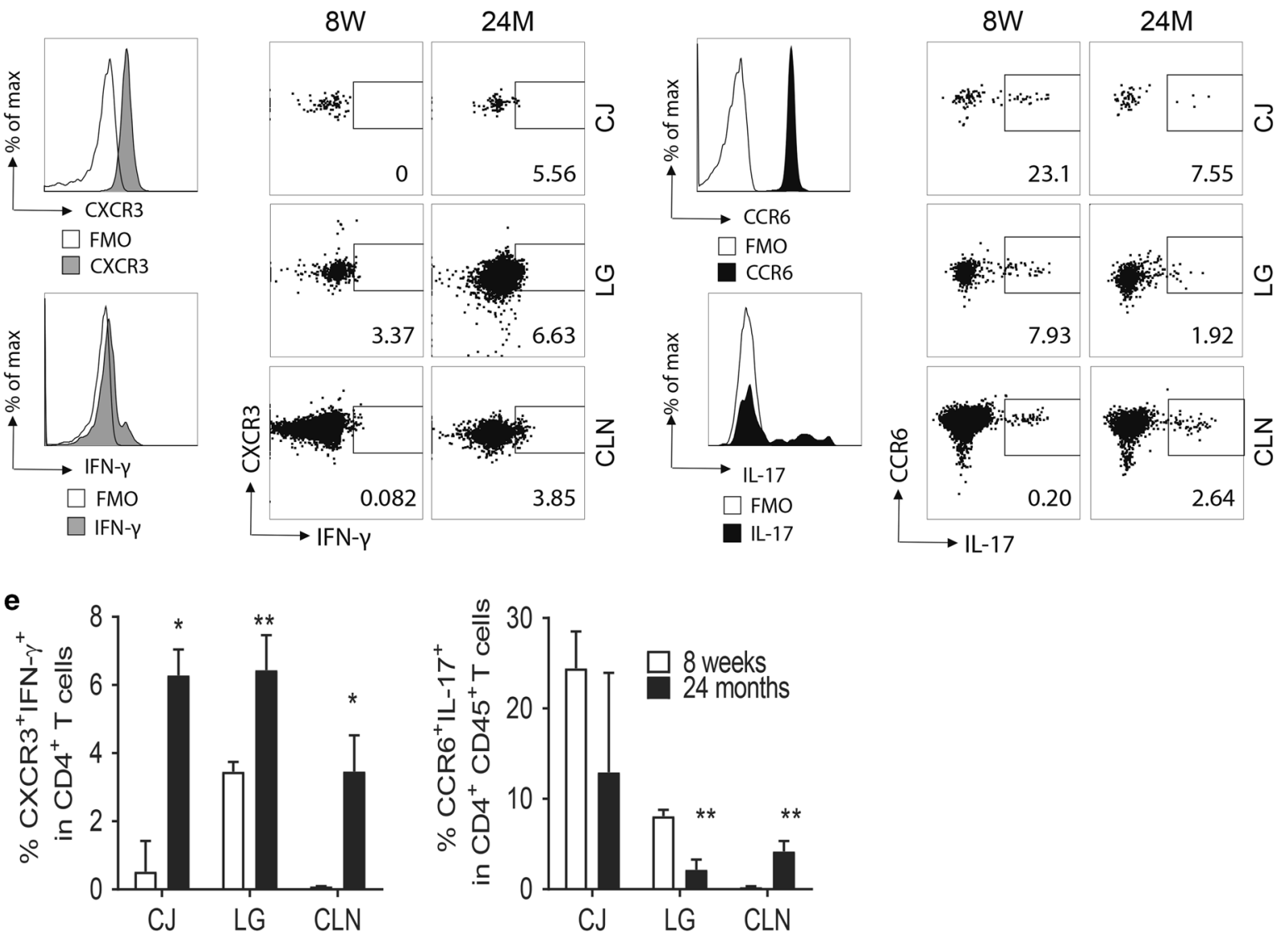

vivarium and were used at 24 months of age. Only mice free of visible tumors were used. RAG1KO ( $n=$ twelve) and OT-II $(n=$ eighteen) mice were used at 6-10 weeks of age. The Institutional Animal Care and Use Committees at Baylor College of Medicine approved all animal experiments. All studies adhered to the Association for Research in Vision and Ophthalmology statement for the Use of Animals in Ophthalmic and Vision Research and to the National Institutes of Health guide for the care and use of Laboratory Animals (NIH Publications No. 8023, revised 1978).
One-hundred and twenty-two B6 female mice per age were used. All efforts were made to collect more than one tissue from the same mouse whenever possible. An exact sample size per test is displayed in the figure legends.

Flow cytometry analysis

Conjunctivas and lacrimal glands were excised and incubated with $0.1 \%$ Collagenase IV as previously described. ${ }^{44}$ Draining nodes were excised and prepared as previously described. ${ }^{66}$ Single cell 
Fig. 5 Accumulation of Th-1 cells in aged mice. Single cell suspensions from either lacrimal gland (LG), and cervical lymph nodes (CLN) were prepared for flow cytometry and stained with CD4 followed by IFN- $\gamma$ or IL-17A intracellular staining. A separate group of mice was used for conjunctiva (CJ), LG and CLN flow cytometry for evaluation of CXCR3 and IFN- $\gamma$ and CCR6 and IL-17A frequencies. a Representative dot plots showing frequency of $\mathrm{CD} 4^{+}, \mathrm{CD} 4^{+} \mathrm{IFN}-\gamma^{+}$, and IFN- $\gamma^{+}$or $\mathrm{CD} 4^{+} \mathrm{IL} 17 \mathrm{~A}^{+}$and IL-17A ${ }^{+}$cells gated from alive single $\mathrm{CD} 45^{+}$cells $(n=$ eight to nine/ age). b Accumulative data showing the frequency of $\mathrm{CD} 4^{+} \mathrm{IFN}-\gamma^{+}$or $\mathrm{CD} 4^{+} \mathrm{IL} 17 \mathrm{~A}^{+}$cells gated on live single $\mathrm{CD} 45^{+}$cells. Means $\pm \mathrm{SEM}, n=$ eight to nine/age; biological replicates from four independent experiments were averaged. c Th-1/Th-17 ratio with aging in LG and CLN. $n=$ eight to nine/age; biological replicates from four independent experiments were averaged. $\mathbf{d}$ Histograms showing positive CXCR3 and IFN- $\gamma$ and CCR6 and IL-17 staining in CLN compared to fluorescence minus one (FMO) controls. Representative dot plots of flow cytometry analysis of conjunctiva, CLN and LG from young and aged B6 mice stained with CD4, followed by CXCR3, and IFN- $\gamma$ or CCR6 and IL-17A staining ( $n=$ four). Numbers are percentiles of positive cells gated on $\mathrm{CD} 4^{+} \mathrm{T}$ cells. e Accumulative data showing the frequency of $\mathrm{CXCR} 3^{+}$IFN- $\gamma^{+}$and $\mathrm{CCR6}^{+} \mathrm{IL}-17^{+}$cells gated on live $\mathrm{CD} 45^{+} \mathrm{CD} 4^{+} \mathrm{T}$ cells. Means $\pm \mathrm{SEM}, n=$ four mice/age; biological replicates from two independent experiments were averaged. ${ }^{*} P<0.05 ;{ }^{* *} P<0.01 ;{ }^{* *} P<0.001 ;{ }^{* * *} P<0.00018 \mathrm{~W}$ vs. $24 \mathrm{M}$ age comparison within each cell type. Two-way ANOVA followed by Sidak's multiple comparison tests

suspensions were incubated with anti-CD16/32 $\left(4^{\circ} \mathrm{C}, 10 \mathrm{~min}\right)$, and subsequently stained using different panels. For the APC panel, cells were stained with CD45_BV510 (clone 30F11, BD Biosciences), CD11C_FITC (Clone HL3, BD Pharmingen, San Diego, CA), CD86_Pacific Blue (clone GL-1, BD Pharmingen), MHC II_PE (clone $\mathrm{I}-\mathrm{A} / \mathrm{I}-\mathrm{E}$, BD Pharmingen), anti-CD103_APC (clone 2E7, Biolegend, San Diego, CA), F4/80_PE-CY5 (clone BM8, ebiosciences/Thermofisher,Waltham, MA), CD11b_PE-Cy7 (clone M1/70, BD Biosciences) antibodies and infra-red lived/dead Fixable Dead Cell Stain ${ }^{\mathrm{TM}}$ (Life Technologies, Grand Island, NY). Cells were kept on ice until analysis on a FACS Canto II System. The gating strategy was: lymphocytes were identified by forward, and side scatter properties, single cells were identified, dead cells were excluded, and $\mathrm{CD}_{4} 5^{+}$cells were identified. CD11 $\mathrm{c}^{+}$cells were then plotted versus $\mathrm{MHC}$ II and further gated into $\mathrm{CD}_{103^{+}}$or $\mathrm{CD} 11 \mathrm{~b}^{+}$cells. $^{37}$ $\mathrm{MHC} \mathrm{II}^{+} \mathrm{CD} 11 \mathrm{c}^{-}$cells were identified and plotted versus F4/80 and $\mathrm{CD} 11 \mathrm{~b}$ to gate $\mathrm{MHC} \mathrm{II}^{+} \mathrm{CD} 11 \mathrm{~b}^{+} \mathrm{F} 4 / 80^{+}$cells. Median fluorescence intensity (MFI) of CD86 staining was then analyzed in these populations.

For intracellular cytokine staining, single cell suspensions were obtained and $10^{6}$ cells were incubated for five hours in the presence of $5 \% \mathrm{CO}_{2}$ with $0.5 \mu \mathrm{L}$ Golgi Stop ${ }^{\mathrm{TM}}$ (BD Bioscience), 0.5 $\mu \mathrm{L}$ Golgi Plug ${ }^{\mathrm{TM}}$ (BD Bioscience), PMA $(0.5 \mu \mathrm{g})$ (Sigma-Aldrich, St. Louis, MO), ionomycin $(0.5 \mu \mathrm{g}$ ) (Sigma) in $1 \mathrm{~mL}$ in complete RPMI 1640. Cells were stained with an infra-red fluorescent reactive dye (Life Technologies, Grand Island, NY) before incubation with a Foxp3 Fixation/Permeabilization working solution (eBioscience) for $18 \mathrm{~h}$ as previously described. ${ }^{67}$ The following antibodies were used: CD4_FITC (clone GK1.5, BD Bioscience), IL17_PE (clone eBio17B7, eBioscience), Foxp3_APC (clone FJK-16S, eBioscience), IFN- $\gamma$ Pacific Blue (clone XMG1.2, Biolegend), CD45_Alexa Fluor ${ }^{\circledR 700}$ (clone 30F11, Biolegend). The gating strategy was: dead cells were excluded by gating live fixable blue dye versus $\mathrm{CD} 45^{+}$cells, and two singlet gates were made. $\mathrm{CD} 4^{+} \mathrm{T}$ cells were gated and frequency of $\mathrm{CD} 4^{+}$Foxp $3^{+}$cells and $\mathrm{CD}^{+}{ }^{+} \mathrm{IFN}-\mathrm{\gamma}^{+}$and $\mathrm{CD} 4^{+} \mathrm{IL}-17 \mathrm{~A}^{+}$calculated among $\mathrm{CD} 4^{+}{ }^{+}$cells. In some experiments, collagenase-digested LGs, conjunctiva, and CLN were stained with CD4_FITC, and CXCR3_PE antibodies (clone 220803, R\&D Systems, Minneapolis, MN) and intracellular staining for IFN- $\gamma$ or IL-17 was performed as above. ${ }^{67}$ Negative controls consisted of fluorescence minus one (FMO) splenocytes.

Cells were acquired with either BD LSR II or BD Canto II Benchtop cytometer with BD Diva software version 6.7 (BD Biosciences). At least 100,000 events or more were collected. Final data were analyzed using FlowJo software version 10 (Tree Star Inc., Ashland, OR).

\section{RNA isolation and Real-time PCR}

Total RNA from isolated cells or conjunctiva (both eyes pooled) was extracted using a QIAGEN RNeasy Plus Micro RNA isolation kit (Qiagen) following the manufacturer's protocol. Five mice per age were pooled, and cells were isolated. One sample equaled a number of remaining cells after isolation. After isolation, the concentration of RNA was measured, and CDNA was synthesized using the Ready-To-Go ${ }^{\mathrm{TM}}$ You-Prime First-Strand kit (GE Healthcare). Real-time PCR was performed using specific MGB Taqman probes for IL-1 $\beta$ (II1b, Mm00434228), IL-12a (IL-12a, Mm00434165), major histocompatibility complex class II (MHCII, Mm00482914), aldehyde dehydrogenase family 1 , subfamily A2 (Aldh1a2, Mm00501306), IFN- $\gamma$ (Ifng, Mm00801778), C-C motif chemokine ligand 2 (CCl2, Mm00441242), C-C motif chemokine ligand 3 (CCl3, Mm00441258), C-C motif chemokine ligand 4 (CCl4, Mm00443111), C-C motif chemokine ligand 22 (CCl22, Mm00436439), C-X-C motif chemokine ligand 13 (CxCl13, Mm00444533), C-X3-C motif chemokine ligand 1 (CX3cl1, Mm00436454) (Taqman Universal PCR Master Mix AmpErase UNG) in a commercial thermocycling system (StepOnePlus ${ }^{\mathrm{TM}}$ Real-Time PCR System, Applied Biosystems), according to the manufacturer's recommendations. The hypoxanthine phosphoribosyltransferase 1 (HPRT1, Mm00446968) gene was used as an endogenous reference for each reaction. The results of quantitative PCR were analyzed by the comparative $\mathrm{Ct}$ method and were normalized by the Ct value of HPRT1. ${ }^{68}$ The young group served as calibrator.

Histology, PAS staining, and IHC

Eyes and ocular adnexa were excised, fixed in 10\% formalin, paraffin embedded and were cut into $5-\mu m$ sections using a microtome (Microm HM 340E, Thermoscientific Wilmington, DE USA). Sections cut from paraffin-embedded globes were stained with Periodic Acid Schiff (PAS) reagent. The goblet cell density was measured in the superior and inferior bulbar and tarsal conjunctiva using NIS-Elements software and expressed as the number of positive cells per millimeter per eyelid. ${ }^{20}$

Immunohistochemistry was performed to detect CD11b, CD11C and MHC II cells in the conjunctiva using CD11b (1:100, clone $M 1 / 70, B D$ Biosciences, San Diego, CA), CD11C (1:100, clone HL3, BD Biosciences) and MHC II (1:100, I-A/I-E, Clone M5/ 114.15.2, BD Pharmingen, San Diego, CA) or IL-1 $\beta$ (1:50, clone D4T2D; Cell Signaling Technology, Danvers, MA) antibodies and appropriate biotinylated secondary antibodies (BD Biosciences) and a Vectastain Elite $A B C$ kit using NovaRed reagents (Vector Laboratories, Burlingame, CA) as previously described. ${ }^{20,69} \mathrm{CD}_{11 \mathrm{c}^{+}}$and $\mathrm{CD} 11 \mathrm{~b}^{+}$cells were counted in the epithelium in three sections taken from five to six different animals of each age that were examined and photographed under 10X magnification with a microscope equipped with a digital camera (Eclipse E400 with a DS-Fi1; Nikon). Individual cells located within the epithelium or immediately below the epithelial basement membrane were counted as positive using image-analysis software (NIS Elements Software, version 3.0, BR). The immunoreactivity to IL-1 $\beta$ was diffuse, and it did not allow for counting individual cells.

Immunofluorescence was performed to detect IL-12 using an IL-12-PE-conjugated antibody (1:100, clone C15.6, 1:100 dilution, BD Pharmingen) using cold acetone fixation and $20 \%$ goat serum as blocking solution. 
$\mathbf{a}$

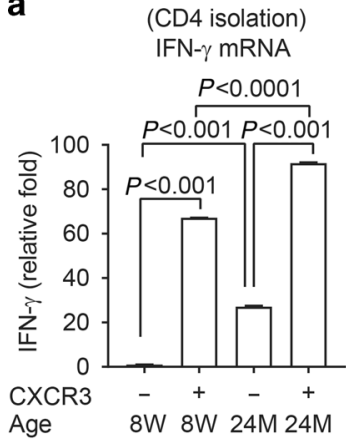

C

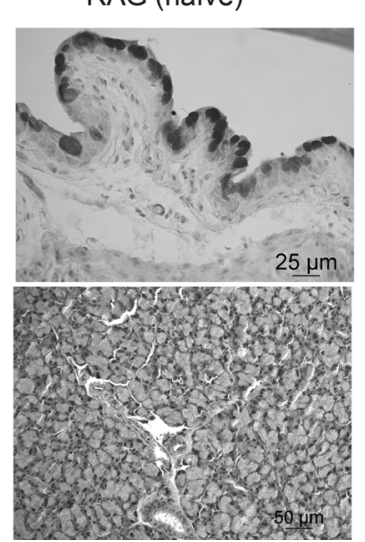

b

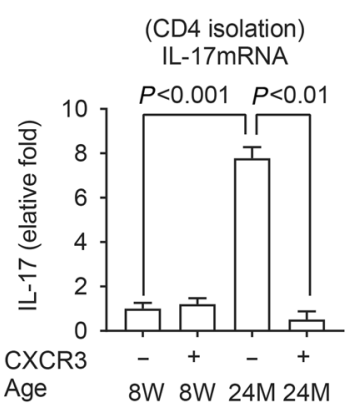

AT $\rightarrow$ RAG

8W CD4+CXCR3 ${ }^{+}$
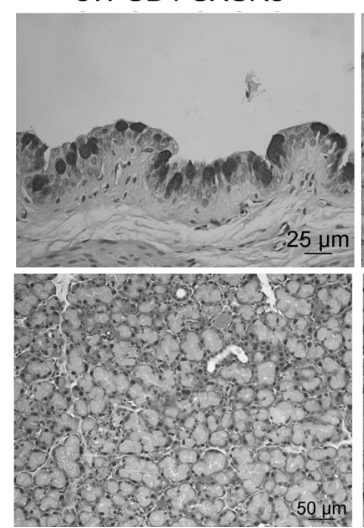

Goblet cell density

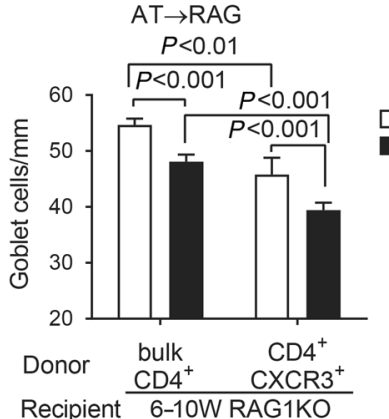

$24 \mathrm{M} \mathrm{CD4}{ }^{+} \mathrm{CXCR}^{+}$

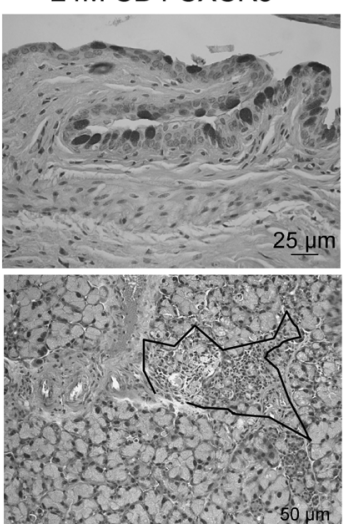

Fig. 6 Adoptive transfer (AT $\rightarrow$ ) of aged Th- 1 cells promote dry eye disease in young immunodeficient mice. $\mathrm{CD}^{+} \mathrm{CXCR} 3^{+}$cells were isolated from cervical lymph nodes (CLN) and spleens from 20 mice/age as described in the methods and were either lysed for gene expression analysis (a) or adoptively transferred into RAG1KO mice (b, c). a Gene expression analysis of $\mathrm{CD}^{+}{ }^{+} \mathrm{CXCR3}^{+}$and $\mathrm{CD} 4^{+} \mathrm{CXCR3}{ }^{-}$cells isolated from $\mathrm{CLN}$ and spleens from young and aged female B6 donor mice before adoptive transfer. Means \pm SD of three samples/age. Mann-Whitney Utest age comparison. $\mathbf{b}$ Number of $\mathrm{PAS}^{+}$conjunctival goblet cells counted in paraffin-embedded palpebral conjunctival sections expressed as number per millimeter in RAG1KO adoptive transfer recipients. Bar graphs show means \pm SD of four to six mice per recipient group; biological replicates from two independent experiments were averaged. Two-way ANOVA followed by Sidak's multiple comparison tests. c Representative image of conjunctival and LG sections from young RAG1KO and adoptive transfer RAG1KO recipients (AT $\rightarrow$ RAG) stained with PAS (purple, conjunctiva, top) or H\&E (LG, bottom)

\section{Aldehyde dehydrogenase activity}

The presence of cells with aldehyde dehydrogenase activity $\left(\mathrm{ALDH} \mathrm{H}^{\text {bright }}\right.$ ) was assessed using the Aldefluor staining kit (StemCell Technologies, Cambridge, MA) following the manufacturer's protocol. Single cell suspensions from either conjunctiva or $\mathrm{CLN}$ were incubated in the dark for $1 \mathrm{~h}$ at $37^{\circ} \mathrm{C}$ in Aldefluor assay buffer containing activated Aldefluor substrate, with or without the ALDH inhibitor, diethylaminobenzaldheyde (DEAB) in ice-cold Aldefluor assay buffer, resuspended in Aldefluor assay buffer containing propidium iodide, and kept on ice until immediate analysis on a FACS Canto II System. Data were analyzed using FlowJo software version 10 (TreeStar Inc., Ashland, OR). For each sample, the total percentage of positive cells was calculated after subtraction of test tube results from control results (cells stained with $D E A B)$. After live/dead staining and singlet discrimination, aldefluor positive cells were gated and analyzed.

Laser scanning confocal scanning microscopy

Freshly harvested whole-mount conjunctivas, with or without preapplication of a $2.5 \mu$ l eye drop of FITC conjugated OVA peptide (OVAp, $5 \mathrm{mg} / \mathrm{mL}$, KareBay Biochem Inc, Monmouth Junction, NJ), to the ocular surface, were fixed in cold methanol and later stained as described using anti-CD11c and anti-CD11b (clone HL3, and clone M1/70, respectively, BD Biosciences, San Diego, CA) antibodies. $^{44}$
Whole mounts of cornea and conjunctiva from young and aged mice ( $n=3$ mice/group) were surgically prepared and fixed with cold methanol and stained with occludin (Zymed, San Francisco, CA) and Alexa Fluor ${ }^{\circledR}$ 488-conjugated goat anti-rabbit antibody. The images were processed using NIS Elements 4.20 version (Nikon).

Digital confocal images were captured with a laser scanning confocal microscope (Nikon A1 RMP, Nikon, Melville, NY) wavelength $400-750 \mathrm{~nm}$ and one $\mu \mathrm{m}$ z-step. The images were processed using NIS Elements 4.20 version (Nikon, Garden City, NY).

Apical cell area in occludin-stained whole mounts was measured in digital images using NIS Elements as previously described. ${ }^{48}$ At least 5-8 cells per image were randomly measured by a masked observer.

Recovery of topically applied antigens at draining nodes

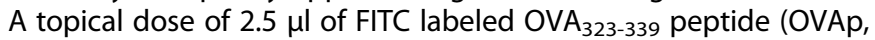
$5 \mathrm{mg} / \mathrm{mL}$, KareBay Biochem Inc, Monmouth Junction, NJ) was topically instilled in each eye of young and aged mice at times 0 and $12 \mathrm{hrs}$ and the animals were euthanized $12 \mathrm{hrs}$ after the second dose ( $24 \mathrm{hrs}$ total) and compared to mice that received vehicle dosing (water). Conjunctivas were excised and incubated with $0.1 \%$ collagenase and prepared for flow cytometry using antiCD16/32, followed by staining with anti-CD45_BV510, anti-MHC 
II_PE, anti-CD11c_APC, and anti-CD11b_PE-Cy7 antibodies. Live cells were suspended in PBS/1\% FBS containing $1 \mu \mathrm{L}$ of violet LIVE/ DEAD Fixable Dead Cell Stain ${ }^{T M}$ (Life Technologies, Grand Island, NY) washed, and kept on ice until flow cytometry analysis. Cells were analyzed with BD Canto II Benchtop cytometer with BD Diva software version 6.7 (BD Biosciences). Final data were analyzed using FlowJo software version 10 (Tree Star Inc., Ashland, OR). Fluorescent minus one controls were used for setting up the gates. The following gating strategy was used in this study: cells were gated by FSC-A (FSC-A) versus SSC-A then sequentially gated into single cells twice (FSC-A vs. height and then SSC-A vs. SSheight). Dead cells were excluded by gating alive $\mathrm{CD}^{+} 5^{+}$cells. CD11c cells were then plotted with MHC II and further gated into

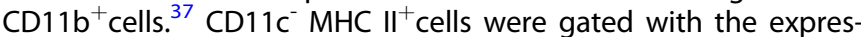

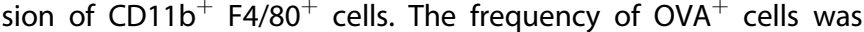
then calculated in both populations.

\section{Cell proliferation assay}

Cervical lymph node suspensions from young and aged B6 mice were prepared and plated at $1.0 \times 10^{5} / 100 \mu \mathrm{l}$ (WST) or $5 \times 10^{5} / 500$ $\mu \mathrm{l}$ (flow cytometry) per well and pulsed with $\mathrm{OVA}_{323-339}$ peptide $\left(10 \mu \mathrm{g} / \mathrm{ml}\right.$, InvivoGen, San Diego, CA) for $1 \mathrm{~h}$. CD4 ${ }^{+}$T cells were isolated from spleens of OT-II mice using the untouched $\mathrm{CD}^{+}{ }^{+} \mathrm{T}$ cell isolation kit according to the manufacturer's instructions (Miltenyi Biotec, Auburn, CA) and plated at $0.5 \times 10^{6}$ in $100 \mu \mathrm{l}$ (WST) or $500 \mu \mathrm{l}$ (flow cytometry) per well in 96-well plates and incubated for 3-4 days. The CD4 enriched cell suspensions contained greater than $93 \% \mathrm{CD}^{+} \mathrm{T}$ cells as determined by flow cytometry (data not shown). Cells were used for flow cytometry, while supernatant media was collected and stored at $-80^{\circ} \mathrm{C}$ until use. In some experiments, cell proliferation was measured by applying the WST-1 reagent (Roche) $24 \mathrm{~h}$ after plating and measured up to $48 \mathrm{~h}$ later.

Multiplex cytokine immunobead assay (Luminex)

Culture assay supernatants were collected, and Luminex assay determined cytokine production. Samples were added to wells containing the appropriate cytokine bead mixture that included mouse monoclonal antibodies specific for IFN- $\gamma$, IL-17 (UpstateMillipore, Billerica, MA) as previously reported. ${ }^{57}$ The reactions were detected with streptavidin-phycoerythrin using a Luminex 100 IS 2.3 system (Austin, TX, USA). The limit of detection for this assay was $3.4 \mathrm{pg} / \mathrm{ml}$ for IFN- $\gamma$, and $3.19 \mathrm{pg} / \mathrm{ml}$ for IL-17.

\section{Adoptive transfer experiments}

Bulk $\mathrm{CD}^{+}{ }^{+} \mathrm{T}$ cells were isolated from spleens and CLN from young and aged B6 mice using magnetic beads according to the manufacturer's instructions (untouched $\mathrm{CD}^{+}{ }^{+} \mathrm{T}$ cell isolation kit, Miltenyi Biotec, Auburn, CA). The CD4 enriched cell suspensions contained $\geq 90 \% \mathrm{CD}^{+}{ }^{+} \mathrm{T}$ cells as determined by flow cytometry (data not shown).

$\mathrm{CD}^{+}{ }^{+} \mathrm{XCR}^{+}$cells were isolated from the spleens and CLN from young and aged B6 mice via a two-step procedure in which $\mathrm{CD} 4^{+}$ $T$ cells were pre-enriched by depletion of unwanted cells using the kit described above. The $\mathrm{CD}^{+}{ }^{+} \mathrm{T}$ cell fraction was then incubated with the anti-CXCR3_PE antibody (R\&D Systems, Minneapolis, MN) and then magnetically labeled with anti_PE microbeads and positively selected for $\mathrm{CD}_{4}^{+} \mathrm{CXCR3}^{+}$cells, according to the manufacturers' instructions (Miltenyi Biotec, Auburn, CA). These cells were used to perform adoptive transfer experiments or collected for quantitative gene expression. Young and aged bulk $\mathrm{CD} 4^{+} \mathrm{T}$ or $\mathrm{CD}^{+}{ }^{+} \mathrm{CXCR}^{+}$cells $\left(2 \times 10^{6}\right)$ were transferred intraperitoneally (i.p.) into 6-10 week old T cell deficient RAG1KO mice. Experiments were performed five weeks after adoptive transfer of bulk $\mathrm{CD}^{+} \mathrm{T}$ cells or $\mathrm{CD}^{+} \mathrm{CXCR3}^{+}$cells. Eyes were collected for goblet cell density analysis and LGs were collected for histology.
Statistical analysis

The sample size was calculated with StatMate Software (GraphPad Software, La Jolla California USA) based on pilot studies. Statistical analyses were performed with Graph Pad Prism software (GraphPad Software, La Jolla California USA, version 7). Data were first evaluated for normality with the Kolmogorov-Smirnov normality test. Appropriate parametric ( $t$-test) or non-parametric (Mann-Whitney) statistical tests were used to make comparisons between two age groups. Whenever adequate, one-way ANOVA followed by Sidak's post hoc test was used. All experiments were repeated at least once. The final sample per experiment is shown in figure legends.

\section{ACKNOWLEDGEMENTS}

This work was supported by the NIH EY026893 (C.S.D.P.), NEI Training Grant in Vision Sciences T32 EY007001-41 (H.H.), NIH EY-002520 (Core Grant for Vision Research Department of Ophthalmology), NIH Training Grant T32-AI053831 (F.B.), Pathology Core Laboratory (NCl P30 CA125123), Biology of Inflammation Center (C.S.D.P.) Research to Prevent Blindness, The Oshman Foundation, William Stamps Farish Fund, The Hamill Foundation, The Sid Richardson Foundation, and by Baylor Cytometry and Cell Sorting Core (NIH NIAID P30AI036211, NCI P30CA125123, and NCRR S10RR024574). We thank Brandon Saxton and Joel Sederstrom who provided expert guidance and assistance with flow cytometry experiments, and Leiqi Zhang for expert management of the aged B6 colony.

\section{AUTHOR CONTRIBUTIONS}

C.S.D.P. designed experiments; H.H., Z.Y., R.G.D.S., Y.X., F.B., F.L.B., C.S.D.P. performed experiments; F.B., F.L.B., Y.X., Z.Y., R.G.D.S., H.H. and C.S.D.P. analyzed data; F.B., S.C.P. and C.S.D.P. wrote the manuscript.

\section{ADDITIONAL INFORMATION}

Competing interests: The authors declare no competing interests.

Publisher's note: Springer Nature remains neutral with regard to jurisdictional claims in published maps and institutional affiliations.

\section{REFERENCES}

1. Schein, O. D. et al. Dry eye and dry mouth in the elderly: a population-based assessment. Arch. Intern. Med. 159, 1359-1363 (1999).

2. Schaumberg, D. A., Sullivan, D. A., Buring, J. E. \& Dana, M. R. Prevalence of dry eye syndrome among US women. Am. J. Ophthalmol. 136, 318-326 (2003).

3. Chotikavanich, S. et al. Production and activity of matrix metalloproteinase- 9 on the ocular surface increase in dysfunctional tear syndrome. Invest. Ophthalmol. Vis. Sci. 50, 3203-3209 (2009)

4. Franceschi, C. et al. Inflamm-aging. An evolutionary perspective on immunosenescence. Ann. NY. Acad. Sci. 908, 244-254 (2000).

5. Carrieri, G. et al. The G/C915 polymorphism of transforming growth factor beta1 is associated with human longevity: a study in Italian centenarians. Aging Cell. 3, 443-448 (2004).

6. Bruunsgaard, $\mathrm{H}$. et al. Predicting death from tumour necrosis factor-alpha and interleukin-6 in 80-year-old people. Clin. Explmmunol. 132, 24-31 (2003).

7. Franceschi, $C$. et al. The network and the remodeling theories of aging: historical background and new perspectives. Exp. Gerontol. 35, 879-896 (2000).

8. Schaumburg, C. S. et al. Ocular surface APCs are necessary for autoreactive T cellmediated experimental autoimmune lacrimal keratoconjunctivitis. J. Immunol. 187, 3653-3662 (2011).

9. Baudouin, C., Brignole, F., Pisella, P. J., De Jean, M. S. \& Goguel, A. Flow cytometric analysis of the inflammatory marker HLA DR in dry eye syndrome: results from 12 months of randomized treatment with topical cyclosporin A. Adv. Exp. Med. Biol. 506(Pt B), 761-769 (2002).

10. Brignole, F. et al. Flow cytometric analysis of inflammatory markers in KCS: 6month treatment with topical cyclosporin A. Invest. Ophthalmol. Vis. Sci. 42, 90-95 (2001).

11. Epstein, S. P., Gadaria-Rathod, N., Wei, Y., Maguire, M. G. \& Asbell, P. A. HLA-DR expression as a biomarker of inflammation for multicenter clinical trials of ocular surface disease. Exp. Eye Res. 111, 95-104 (2013).

12. Yang, S. et al. Interferon-gamma-induced intestinal epithelial barrier dysfunction by NF-kappaB/HIF-1alpha pathway. J. Interferon Cytokine Res. 34, 195-203 (2014). 
13. Beaurepaire, C., Smyth, D. \& McKay, D. M. Interferon-gamma regulation of intestinal epithelial permeability. J. Interferon Cytokine Res. 29, 133-144 (2009).

14. Lam, H. et al. Tear Cytokine Profiles in Dysfunctional Tear Syndrome. Am. J. Ophthalmol. 147, 198-205 (2009).

15. Pflugfelder, S. C. et al. Aqueous tear deficiency increases conjunctival interferon- $\gamma$ (IFN- $\gamma$ ) expression and goblet cell loss. Invest. Ophthalmol. Vis. Sci. 56, 7545-7550 (2015).

16. Tsubota, K. et al. Regulation of human leukocyte antigen expression in human conjunctival epithelium. Invest. Ophthalmol. Vis. Sci. 40, 28-34 (1999).

17. Chen Y., et al. IFN-gamma-Expressing Th17 Cells Are Required for Development of Severe Ocular Surface Autoimmunity. J. Immunol. 199, 1163-1169 (2017).

18. Pelegrino, F. S. et al. Deletion of interferon-gamma delays onset and severity of dacryoadenitis in CD25KO mice. Arthritis Res. Ther. 14, R234 (2012).

19. Cha, S. et al. A dual role for interferon-gamma in the pathogenesis of Sjogren's syndrome-like autoimmune exocrinopathy in the nonobese diabetic mouse. Scand. J. Immunol. 60, 552-565 (2004).

20. de Paiva, C. S. et al. Dry eye-induced conjunctival epithelial squamous metaplasia is modulated by interferon- $\gamma$. Invest. Ophthalmol. Vis. Sci. 48, 2553-2560 (2007).

21. Zhang, $X$. et al. Topical interferon-gamma neutralization prevents conjunctival goblet cell loss in experimental murine dry eye. Exp. Eye Res. 118, 117-124 (2014).

22. Coursey, T. G., Henriksson, J. T., Barbosa, F. L., de Paiva, C. S. \& Pflugfelder, S. C. Interferon-gamma-induced unfolded protein response in conjunctival goblet cells as a cause of mucin deficiency in Sjogren syndrome. Am. J. Pathol. 186, 1547-1558 (2016).

23. Garcia-Posadas, L. et al. Interaction of IFN-gamma with cholinergic agonists to modulate rat and human goblet cell function. Mucosal Immunol. 9, 206-217 (2016).

24. Xiao, Y., et al. Goblet cell produced retinoic acid suppresses CD86 expression and IL-12 production in bone marrow derived cells. Int. Immunol. 30, 457-470 (2018).

25. Contreras-Ruiz, L. \& Masli, S. Immunomodulatory cross-talk between conjunctival goblet cells and dendritic cells. PLoS ONE 10, e0120284 (2015).

26. Contreras-Ruiz, L., Ghosh-Mitra, A., Shatos, M. A., Dartt, D. A. \& Masli, S. Modulation of conjunctival goblet cell function by inflammatory cytokines. Mediat. Inflamm. 2013, 636812 (2013).

27. McClellan, A. J. et al. Ocular surface disease and dacryoadenitis in aging C57BL/6 mice. Am. J. Pathol. 184, 631-643 (2014).

28. Volpe, E. A. et al. Interferon-gamma deficiency protects against aging-related goblet cell loss. Oncotarget. 7, 64605-66461 (2016).

29. Moss, S. E., Klein, R. \& Klein, B. E. Prevalence of and risk factors for dry eye syndrome. Arch. Ophthalmol. 118, 1264-1268 (2000).

30. Stichel, C. C. \& Luebbert, H. Inflammatory processes in the aging mouse brain: participation of dendritic cells and T-cells. Neurobiol. Aging. 28, 1507-1521 (2007).

31. Agrawal, A. \& Gupta, S. Impact of aging on dendritic cell functions in humans. Ageing. Res. Rev. 10, 336-345 (2011).

32. Zhang, X. et al. NK cells promote Th-17 mediated corneal barrier disruption in dry eye. PLOS ONE 7, e36822 (2012).

33. Endlich, B., Armstrong, D., Brodsky, J., Novotny, M. \& Hamilton, T. A. Distinct temporal patterns of macrophage-inflammatory protein-2 and $\mathrm{KC}$ chemokine gene expression in surgical injury. J. Immunol. 168, 3586-3594 (2002).

34. Mariani, E. et al. RANTES and MIP-1alpha production by T lymphocytes, monocytes and NK cells from nonagenarian subjects. Exp. Gerontol. 37, 219-226 (2002).

35. Ishikawa, S. et al. Aberrant high expression of B lymphocyte chemokine (BLC/ CXCL13) by $\mathrm{C} 11 \mathrm{~b}+\mathrm{CD} 11 \mathrm{c}+$ dendritic cells in murine lupus and preferential chemotaxis of B1 cells towards BLC. J. Exp. Med. 193, 1393-1402 (2001).

36. Ishikawa, S. et al. Increased circulating CD11b + CD11c + dendritic cells (DC) in aged BWF1 mice which can be matured by TNF-alpha into BLC/CXCL13-producing DC. Eur. J. Immunol. 32, 1881-1887 (2002).

37. Khandelwal, P. et al. Ocular mucosal CD11b + and CD103 + mouse dendritic cells under normal conditions and in allergic immune responses. PLOS ONE 8, e64193 (2013).

38. Franceschi, C. \& Campisi, J. Chronic inflammation (inflammaging) and its potential contribution to age-associated diseases. J. Gerontol. A. Biol. Sci. Med. Sci. 69(Suppl 1), S4-S9 (2014)

39. Ahadome S. D., et al. Classical dendritic cells mediate fibrosis directly via the retinoic acid pathway in severe eye allergy. JCI Insight. 1, e87012 (2016).

40. Guilliams, M. et al. Skin-draining lymph nodes contain dermis-derived CD103(-) dendritic cells that constitutively produce retinoic acid and induce Foxp3 $(+)$ regulatory T cells. Blood 115, 1958-1968 (2010).

41. Coombes, J. L. \& Powrie, F. Dendritic cells in intestinal immune regulation. Nat. Revimmunol. 8, 435-446 (2008).
42. Coombes, J. L. et al. A functionally specialized population of mucosal CD103+ DCs induces Foxp3 + regulatory $T$ cells via a TGF-beta and retinoic aciddependent mechanism. J. Exp. Med. 204, 1757-1764 (2007).

43. Belkaid, Y. \& Oldenhove, G. Tuning microenvironments: induction of regulatory T cells by dendritic cells. Immunity 29, 362-371 (2008).

44. Barbosa, F. L. et al. Goblet cells contribute to ocular surface immune toleranceimplications for dry eye disease. Int. J. Mol. Sci. 18, 1-13 (2017).

45. Yi, X., Wang, Y. \& Yu, F. S. Corneal epithelial tight junctions and their response to lipopolysaccharide challenge. Invest. Ophthalmol. Vis. Sci. 41, 4093-4100 (2000).

46. Yap, A. S., Mullin, J. M. \& Stevenson, B. R. Molecular analyses of tight junction physiology: insights and paradoxes. J. Membr. Biol. 163, 159-167 (1998).

47. de Paiva, C. S. et al. Apical corneal barrier disruption in experimental murine dry eye is abrogated by methylprednisolone and doxycycline. Invest. Ophthalmol. Vis. Sci. 47, 2847-2856 (2006).

48. Beardsley, R. M., de Paiva, C. S., Power, D. F. \& Pflugfelder, S. C. Desiccating stress decreases apical corneal epithelial cell size--modulation by the metalloproteinase inhibitor doxycycline. Cornea 27, 935-940 (2008).

49. Chauhan, S. K. et al. Autoimmunity in dry eye is due to resistance of Th17 to Treg suppression. J. Immunol. 182, 1247-1252 (2009).

50. Chen, Y., Chauhan, S. K., Tan, X. \& Dana, R. Interleukin-7 and -15 maintain pathogenic memory Th17 cells in autoimmunity. J. Autoimmun. 77, 96-103 (2017).

51. Zhang, X. et al. Interferon-gamma exacerbates dry eye-induced apoptosis in conjunctiva through dual apoptotic pathways. Invest. Ophthalmol. Vis. Sci. 52, 6279-6285 (2011).

52. Zhang, X. et al. Desiccating stress induces CD4(+) T-cell-mediated Sjogren's syndrome-like corneal epithelial apoptosis via activation of the extrinsic apoptotic pathway by interferon-gamma. Am. J. Pathol. 179, 1807-1814 (2011).

53. Wang, C., Kang, S. G., Lee, J., Sun, Z. \& Kim, C. H. The roles of CCR6 in migration of Th17 cells and regulation of effector T-cell balance in the gut. Mucosal Immunol. 2, 173-183 (2009).

54. O'Garra, A., McEvoy, L. M. \& Zlotnik, A. T-cell subsets: Chemokine receptors guide the way. Curr. Biol. 8, R646-R649 (1998).

55. Hirota, K. et al. Preferential recruitment of CCR6-expressing Th17 cells to inflamed joints via CCL20 in rheumatoid arthritis and its animal model. J. Exp. Med. 204, 2803-2812 (2007).

56. Niederkorn, J. Y. et al. Desiccating stress induces T cell-mediated Sjogren's syndrome-like lacrimal keratoconjunctivitis. J. Immunol. 176, 3950-3957 (2006).

57. Coursey, T. G. et al. Age-related spontaneous lacrimal keratoconjunctivitis is accompanied by dysfunctional T regulatory cells. Mucosal Immunol. 10, 743-456 (2017).

58. de Paiva, C. S. et al. Homeostatic control of conjunctival mucosal goblet cells by NKT-derived IL-13. Mucosal Immunol. 4, 397-408 (2011).

59. Lemp, M. A., Dohlman, C. H., Kuwabara, T., Holly, F. J. \& Carroll, J. M. Dry eye secondary mucus deficiency. Trans. Am. Ophthalmol. Soc. 75, 1223-1227 (1971).

60. Ralph, R. A. Conjunctival goblet cell density in normal subjects and in dry eye syndromes. Invest. Ophthalmol. 14, 299-302 (1975).

61. Ko, B. Y., Xiao, Y., Barbosa, F. L., de Paiva, C. S. \& Pflugfelder, S. C. Goblet cell loss abrogates ocular surface immune tolerance. JCI Insight. 3, 98222 (2018).

62. Prakash, S. et al. Dendritic cells from aged subjects contribute to chronic airway inflammation by activating bronchial epithelial cells under steady state. Mucosal Immunol. 7, 1386-1394 (2014).

63. Manicassamy, S. et al. Toll-like receptor 2-dependent induction of vitamin Ametabolizing enzymes in dendritic cells promotes $T$ regulatory responses and inhibits autoimmunity. Nat. Med. 15, 401-409 (2009).

64. Du, X. et al. An essential role for Rxr alpha in the development of Th2 responses. Eur. J. Immunol. 35, 3414-3423 (2005).

65. Dohlman, T. H. et al. The CCR6/CCL20 axis mediates Th17 cell migration to the ocular surface in dry eye disease. Invest. Ophthalmol. Vis. Sci. 54, 4081-4091 (2013).

66. Bian, F. et al. Altered balance of interleukin-13/interferon-gamma contributes to lacrimal gland destruction and secretory dysfunction in CD25 knockout model of Sjogren's syndrome. Arthritis Res. Ther. 17, 53 (2015).

67. Zaheer, M. et al. Protective role of commensal bacteria in Sjogren Syndrome. J. Autoimmun. pii: S0896-8411, 30179-30173 (2018).

68. Coursey, T. G., Bohat, R., Barbosa, F. L., Pflugfelder, S. C. \& de Paiva, C. S. Desiccating stress-induced chemokine expression in the epithelium is dependent on upregulation of NKG2D/RAE-1 and release of IFN-gamma in experimental dry eye. J. Immunol. 193, 5264-5272 (2014).

69. Zhang, X. et al. CD8 $(+)$ cells regulate the $T$ helper-17 response in an experimental murine model of Sjogren syndrome. Mucosal Immunol. 7, 417-427 (2014). 